\title{
Article \\ Use of Computed Tomography Scan Technology to Explore the Porosity of Concrete: Scientific Possibilities and Technological Limitations
}

\author{
Miguel Angel Vicente*(D), Álvaro Mena Desús Mínguez and Dorys Carmen González \\ E. Politécnica Superior, Campus Milanera (Edif. D), Universidad de Burgos, C/Villadiego s/n, \\ 09001 Burgos, Spain; amena@ubu.es (Á.M.); jminguez@ubu.es (J.M.); dgonzalez@ubu.es (D.C.G.) \\ * Correspondence: mvicente@ubu.es; Tel.: +34-947-25-94-23
}

Citation: Vicente, M.A.; Mena, Á.; Mínguez, J.; González, D.C. Use of Computed Tomography Scan

Technology to Explore the Porosity of Concrete: Scientific Possibilities and Technological Limitations. Appl. Sci. 2021, 11, 8699. https://doi.org/ 10.3390/app11188699

Academic Editor: Dario De Domenico

Received: 23 August 2021

Accepted: 16 September 2021

Published: 18 September 2021

Publisher's Note: MDPI stays neutral with regard to jurisdictional claims in published maps and institutional affiliations.

Copyright: (c) 2021 by the authors. Licensee MDPI, Basel, Switzerland. This article is an open access article distributed under the terms and conditions of the Creative Commons Attribution (CC BY) license (https:// creativecommons.org/licenses/by/ $4.0 /)$.

\begin{abstract}
This paper shows the scientific possibilities of computed tomography for the study of concrete porosity. The enormous technological advances in computed tomography equipment used in materials research, with increasingly higher energy, better resolution and smaller pixel size will allow, in the near future, viewing pore sizes that are currently unthinkable, competing in resolution with the traditional techniques of mercury porosimetry and nitrogen adsorption. The challenge at that time (and to a lesser extent today) will be how to extract as much information as possible from the large amount of data provided by computed tomography equipment. In this article, through the study of six cubic specimens of $40 \mathrm{~mm}$ sides, different techniques of extraction and presentation of the information are shown, which help us to better understand the characterization of the morphology and distribution of the pores inside the concrete matrix. This information is essential to understand some of the macroscopic responses of the concrete.
\end{abstract}

Keywords: CT-scan technology; porosity; circumferential test; neighborhood test; porosimetric curve; maximum pore size; pore orientation

\section{Introduction}

Computed tomography (CT) scanning is a non-destructive technique used to characterize the internal structure of matter on a microscopic scale. This method is based on the attenuation or loss of energy that X-rays undergo as they pass through matter, which is governed by the Beer-Lambert law (Equation (1)).

$$
I=I_{0} \cdot \exp \left[-\int \mu(s) d s\right]
$$

where $I$ is the final intensity of the X-ray, $I_{0}$ is the incident intensity and $\mu(s)$ is the linear attenuation coefficient along its path. This last parameter basically depends on the density $\rho$ of the matter crossed by the X-ray during that path. It can be found that the ratio $\mu / \rho$ is approximately proportional to $Z^{3}$, where $Z$ is the atomic number of the element.

Therefore, the basic operating principle of $\mathrm{CT}$ is the direct relationship between the energy attenuation of X-rays and the density of the matter they pass through. A CT scan consists of two basic elements: an X-ray source of adjustable intensity and an intensity detector. The specimen is placed between the two and during the scanning process is passed through by X-ray beams in different directions and at different heights [1-4].

Beyond its well-known application in medicine, the use of computed tomography to explore the microstructure of materials is becoming increasingly widespread. In addition to the enormous possibilities it provides for materials research, the equipment is becoming more and more affordable. 
No branch of engineering is alien to this technology, and almost any material has been studied using this technique, from metals or plastics to composites or rocks [5-10]. A detailed review of the state of the art in this field can be found in [11,12].

Concrete is also no stranger to this trend. In recent years there has been an increase in the use of computed tomography for the study of its microstructure in order to analyze how it affects its macroscopic response [13-17].

Within the microstructure of concrete there are two singular elements whose influence on its macroscopic response is well known: pores and fibers.

Fibers can only be found in fiber-reinforced concretes. However, pores are present in all concretes. In most cases, this is an unintended "component"; nevertheless, there are other situations where concretes are designed with a certain level of porosity. This occurs, for example, in pervious concretes used mainly in concrete pavements [18-20] or in porous concretes to improve their response to freeze-thaw cycles [21-23].

Figure 1 shows the trend of scientific papers published between 2001 and 2021 in the most relevant fields applying CT. All data were obtained from WoS (Web of Science) [24], a widely used bibliographic database that collects the most influential international journals in all fields of science and technology.

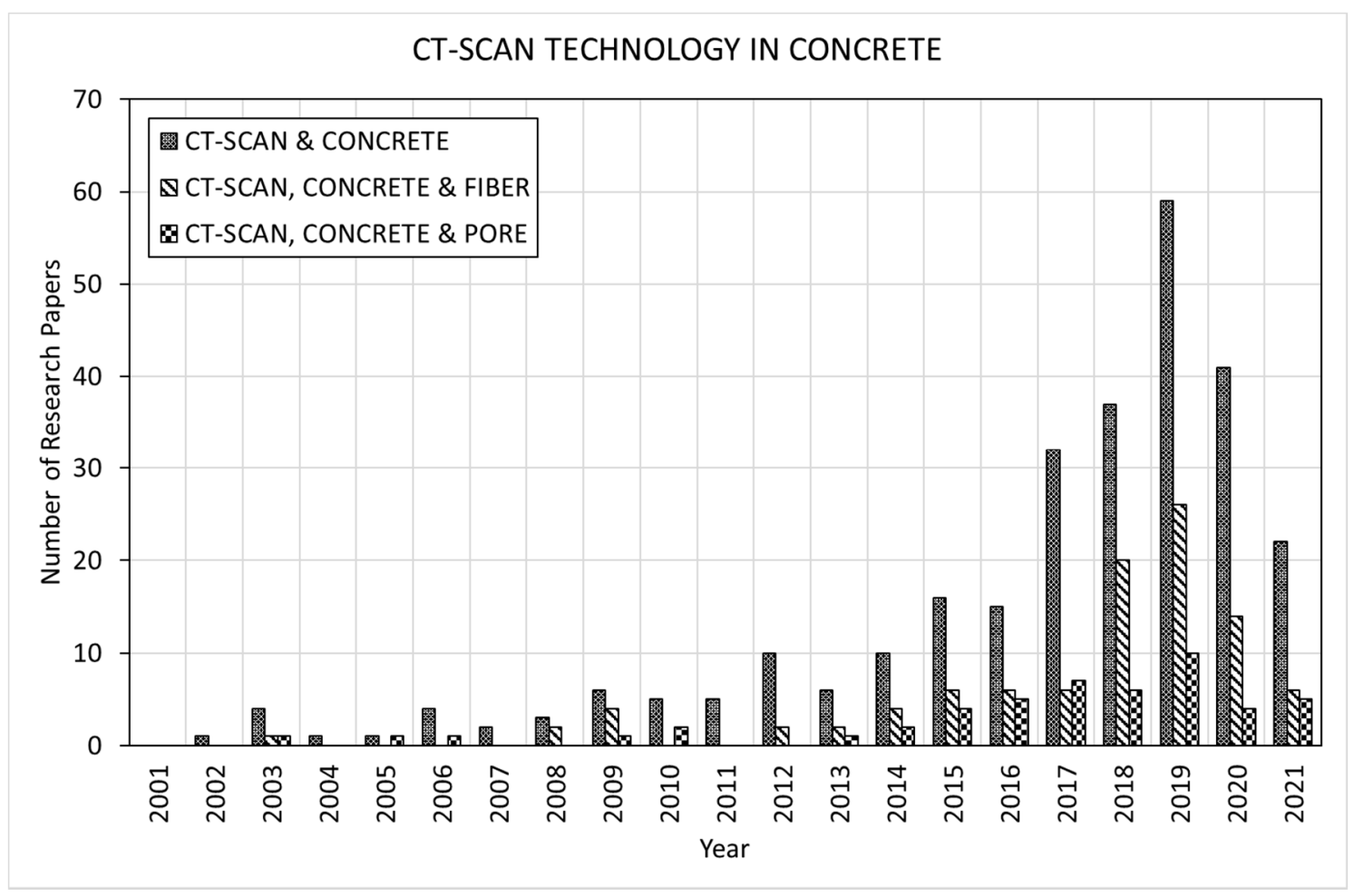

Figure 1. Evolution in the number of scientific publications related to computed tomography in concrete (2001-2021).

Figure 1 reveals how most of the research works on concrete microstructure using computed tomography focus on the study of fiber orientation and distribution, while only a small percentage of them focus on porosity.

This is due to the fact that the resolution of the computed tomography equipment provided by the market so far shows insufficient resolutions.

According to IUPAC, pores can be classified according to their size into micropores (smaller than $2 \mathrm{~nm}$ ), mesopores (from 2 to $50 \mathrm{~nm}$ ) and macropores (larger than $50 \mathrm{~nm}$ ) [25-28]. The pores that have the greatest influence on the macroscopic response of concrete are micropores and mesopores. Macropores have a minor influence. There is one exception: pervious concretes. In this case, the largest pores are the most important, although what is sought in this type of concrete is its hydraulic capacity and not so much its structural response. 
The last ten years have seen an impressive development in computed tomography equipment. Resolution has improved significantly, from around $100 \mu \mathrm{m}$ a decade ago to $1 \mu \mathrm{m}$ today. The energy of the device has also greatly increased, leading to improved image quality and larger specimen sizes. In addition, there have been very notable advances in the capacity and speed of postprocessing the information provided by the tomography equipment.

However, current technology still has shortcomings in the study of concrete porosity. The first is resolution: although a resolution of $1 \mu \mathrm{m}$ is a very small value, it is not sufficient to study mesopores, much less micropores. Moreover, such a high resolution can only be achieved on very small specimens, which limits its use in concrete. The technical challenge for the next decade is to scan specimens of normal size $(10-30 \mathrm{~cm})$ at resolutions well below $1 \mu \mathrm{m}$.

At present, two traditional techniques are used to analyze porosity in concretes, namely nitrogen adsorption and mercury-intrusion porosimetry (MIP) [29-32]. These techniques can measure really small pore sizes, down to $10 \mathrm{~nm}$ or even less, but show important limitations. They can only provide the pore-size distribution, but neither their spatial distribution nor their morphological parameters. Moreover, the information that they provide is related to the open porosity and not to the closed one, which is more interesting when studying this phenomenon.

The possibilities for study and research offered by computed tomography are enormously greater than those that traditional techniques can afford, and it is only a matter of time before technology provides science with computed tomography equipment with resolutions of the order of $1 \mathrm{~nm}$.

At that time, and actually also right now with the technology available, the next step is to explore what information can be obtained from the large volume of raw data supplied by the tomography equipment.

In general terms, the tomography equipment provides a 3D image of the specimen. This image is in fact a set of voxels that are assigned a gray color according to their relative density, so that the voxel corresponding to the lowest density point of the specimen is assigned the color black while the voxel corresponding to the highest density point is assigned the color white. Basically, the file given by the tomography equipment is nothing more than a huge data matrix of millions of rows and only four columns, in which each row contains the $X, Y$, and Z coordinates of the voxel's center of gravity and a gray number, depending on its average density. In the case of 16-bit images, the gray value 0 corresponds to black (or the least dense point) and the gray value 65,535 corresponds to white (or the densest point). In addition, the file provides some interesting metadata, most notably the voxel size (i.e., the length of the side of the voxel).

From this point on, data post-processing begins in order to obtain all the information that the scan can provide. The first step is to identify which voxels correspond to pores and which do not. To do this, a gray threshold must be defined, so that all voxels whose gray level is higher than this threshold are discarded (remember that the darkest voxels are the least dense). The second step is to group all voxels that are in contact, i.e., those whose distance between centers of gravity is under a certain value. Additionally, filters can be applied to separate pores that the software interprets as connected but which are in fact clearly independent entities (e.g., pores connected by a thin neck). One of the best-known techniques is the watershed segmentation [33].

At this stage, all the pores have been identified and isolated. Additionally, everything is ready to start extracting the information that is of real interest.

This paper attempts to show some of the most interesting techniques to analyze pores and to extract the maximum information, quantitative and not only qualitative, provided by this technology. Obviously, the simple observation of the images supplied by the computed tomography equipment can give us interesting information, but it is much more useful and rigorous to extract the information in a quantitative way. 
To illustrate the postprocessing possibilities, six cubic specimens of $40 \mathrm{~mm}$ sides made of fiber-reinforced concrete were scanned and postprocessed using different algorithms and procedures.

This paper shows different analyses that can be carried out on these specimens, with the aim of demonstrating the technological capabilities of computed tomography when studying pores in concrete.

The structure of the paper is as follows: the experimental program is presented in Section 2, the test results are described and discussed in Section 3, and finally the conclusions are shown in Section 4.

\section{Experimental Program}

For this work, a total of 6 cubic specimens of $40 \mathrm{~mm}$ sides were scanned. These specimens were cut from a prismatic piece of $150 \times 150 \times 600 \mathrm{~mm}$ (Figure 2). Therefore, the microstructure of all the specimens is expected to be very similar.

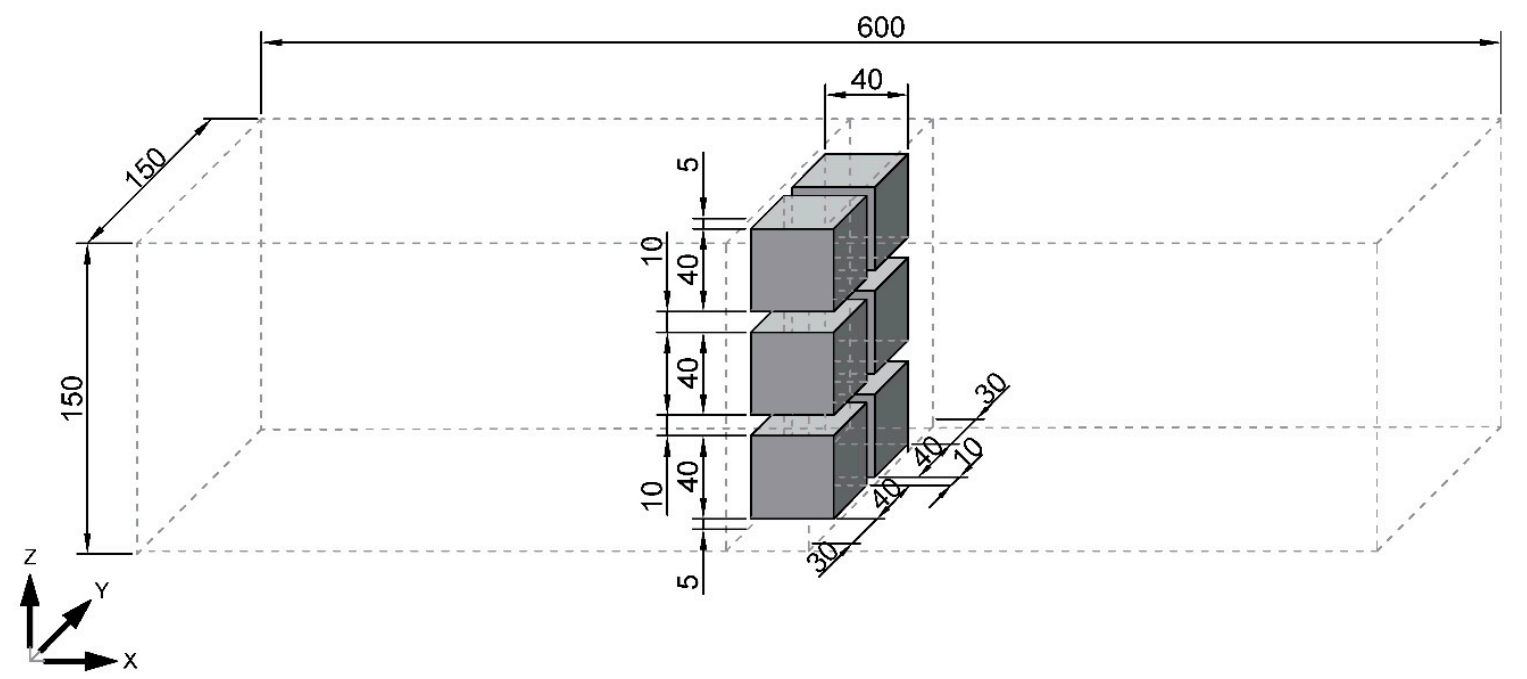

Figure 2. Specimens cut from the prism. Dimensions in $\mathrm{mm}$.

The material used in the study was a self-compacting concrete reinforced with steel fibers. The proportion of fibers was $0.3 \%$ by volume and its type was Dramix OL $13 / .20$ straight fibers from Bekaert (Zwevegem, Belgium), $13 \mathrm{~mm}$ in length and with an aspect ratio of 65 . This length was chosen so that the fibers would be short enough with respect to the smallest specimen size to maintain the homogeneity of mechanical properties in this volume of material. In the same vein, the maximum aggregate size was limited to $8 \mathrm{~mm}$.

The concrete mix was designed for a compressive strength of $30 \mathrm{MPa}$ in $100 \mathrm{~mm}$ cubes. The dosage of the concrete mix is presented in Table 1.

With the hardened concrete, the average compressive strength obtained at 28 days was $26.4 \pm 1 \mathrm{MPa}$ in cylinders of $75 \mathrm{~mm}$ diameter and $150 \mathrm{~mm}$ height, and $28.2 \pm 1 \mathrm{MPa}$ in cubes of $100 \mathrm{~mm}$ side. The elastic modulus and Poisson's ratio were also measured using the cylindrical specimens, resulting in $17.4 \pm 1 \mathrm{GPa}$ and $0.16 \pm 0.01$, respectively. The properties were very homogeneous as evidenced by the reduced standard deviations.

A MicroCT Phoenix V I Tome I X s 240 unit from GE Sensing \& Inspections Technologies (Boston, MA, USA), equipped with a high-power nanofocus X-ray tube $(180 \mathrm{kV} / 20 \mathrm{~W})$ and a high-power microfocus tube $(240 \mathrm{kV} / 320 \mathrm{~W})$, was used for scanning. 
Table 1. Dosage of the concrete mix.

\begin{tabular}{|c|c|}
\hline Component & Content $\left(\mathrm{kg} / \mathrm{m}^{3}\right)$ \\
\hline CEM II/B-L $32.5 \mathrm{~N}$ cement & 286 \\
\hline Water & 202 \\
\hline MasterEase 5025 superplasticizer & 2.86 \\
\hline MasterCast 212 air reducer & 1.00 \\
\hline Dramix OL $13 / .20$ steel fibers & 23.55 \\
\hline $12 \mu \mathrm{m}$ OMYA filler & 195 \\
\hline $0.5 \mathrm{~mm}$ feldspathic sand & 921 \\
\hline 4-8 mm coarse aggregate & 712 \\
\hline
\end{tabular}

By using a post-processing software package, a total of 1334 2D slices with pixel sizes of $2048 \times 2048$ (Figure 3) were obtained throughout the height of each specimen from the CT-scan data. The resolution, understood as voxel size, was approximately $30 \times 30 \times 30 \mu^{3}$. The specimens were scanned one after each other and the geometry of the irradiation was cone beam. In this case, only the high-power nanofocus was used.

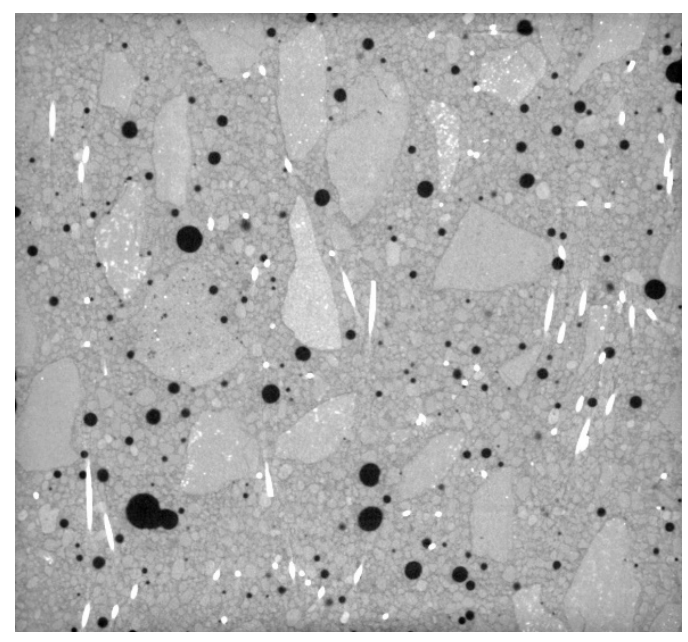

Figure 3. Example of one 2D slice.

A 3D image of each entire specimen was generated by using all the above-mentioned 2D images (Figure 4). The post-processing software assigned a grey value to each voxel, from 0 (which belongs to the least dense voxel, i.e., void) to 65,535 (which belongs to the densest voxel).

The data from the scanning process were saved in a file that included the $\mathrm{X}, \mathrm{Y}$, and $\mathrm{Z}$ Cartesian coordinates of the center of gravity of all voxels and an integer, from 0 to 65,535 , with regard to their density. The total number of voxels in each specimen was approximately $2.4 \times 10^{9}$. 


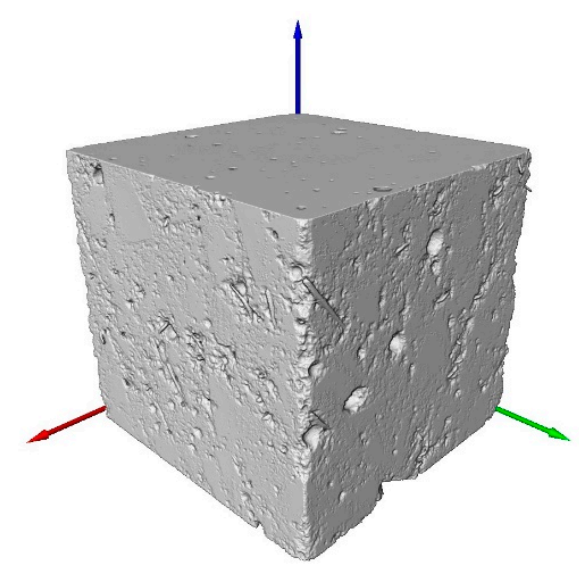

Figure 4. Example of 3D reconstruction.

\section{Results and Discussion}

Once all the cubes had been scanned, an initial processing of the information was carried out. The commercial software AVIZO (FEI Visualization Sciences Group, Hillsboro, OR, USA) was used for this purpose.

First, we proceeded to extract all the voxels belonging to the pores, which were defined on the basis of a certain gray level. In this case, an upper gray threshold of 5500 was considered appropriate. Therefore, all voxels whose gray level was between 0 and 5500 were considered as pores. As a general criterion, the gray threshold is taken in a valley of the gray distribution histogram, since the valleys correspond to the boundaries between the different components of the material.

Next, all the voxels that were in contact were added. Subsequently, we proceeded to separate all those pores that had been joined by small necks. In these cases, the voxel aggregation subroutine results in one pore when in fact there are two pores very close to each other. An algorithm based on watershed segmentation [33] was applied. The final result is shown in Figure 5.

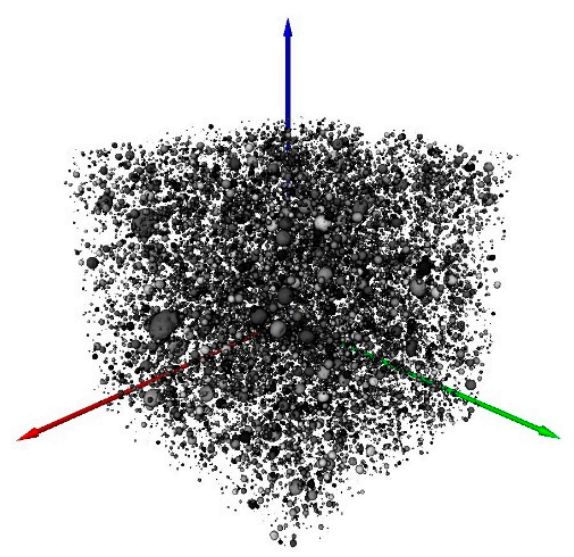

Figure 5. Pores identified and isolated.

At this point, the aforementioned postprocessing software provides the following information for each pore: $X, Y, Z$ coordinates of its center of gravity; pore length, defined as the longest distance that can be established between two voxels; width, defined as the shortest distance between two contour voxels; pore volume; outer surface area; and orientation. Elements with a length of less than $100 \mu \mathrm{m}$ were discarded, which corresponds to approximately three times the voxel size.

Regarding pore orientation, it is obtained from AVIZO in Spherical coordinates; that is, the angular information it provides are the values of $\theta$ (theta) and $\phi$ (phi) (Figure 6a). Theta is the polar angle, i.e., the angle between the principal axis of the pore (the one containing 
its length) and the vertical $\mathrm{Z}$ axis. It should be noted that the vertical axis corresponds to the concreting direction and also to the loading direction. Phi is the azimuthal angle, i.e., the angle between the projection of the principal axis on the $X Y$ plane and the $X$ axis. Theta varies from $0^{\circ}$ to $90^{\circ}$ while phi varies from $-90^{\circ}$ to $90^{\circ}$.
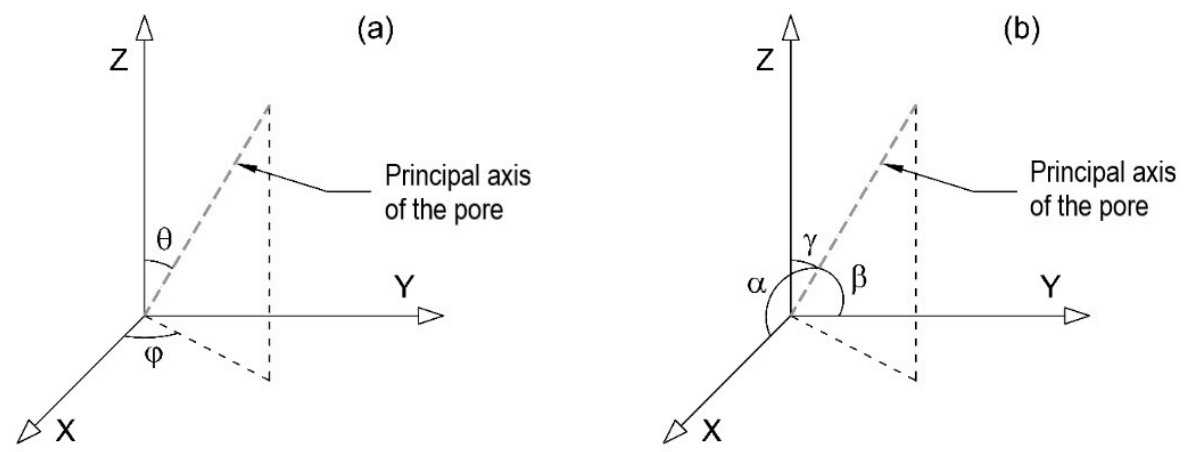

Figure 6. Identification of $\theta$ (theta) and $\phi$ (phi) angles in Spherical coordinates (a), and of $\alpha$ (alpha), $\beta$ (beta) and $\gamma$ (gamma) angles in Cartesian coordinates $(\mathbf{b})$.

Using this information, the pore orientation can be obtained according to the Cartesian angles, $\alpha$ (alpha), $\beta$ (beta) and $\gamma$ (gamma) (Figure 6b).

From the basic data provided by the software it is possible to obtain much more information to understand the morphological characteristics of the pores and their spatial distribution. Some of the main techniques and procedures to obtain such information are described in detail below.

\subsection{Circumferential Test}

The circumferential test is a procedure developed by Vicente et al. in 2018 [34] to determine the degree of homogeneity in the distribution of damage within intact specimens and specimens tested to failure. This method can also be applied to pores in order to know their distribution inside the specimen.

In a simplified manner, in the circumferential test, the pore position is replaced by a numerical value $L$ corresponding to the distance between its center of gravity and an axis parallel to the vertical axis $Z$ passing through the center of gravity of the specimen. In order to be able to compare specimens of different sizes, the coefficient $L$ is made dimensionless by defining the coefficient $l$, which is obtained according to the following expression (Equation (2)):

$$
l=\sqrt{\left(\frac{x-x_{\operatorname{cog}}}{a}\right)^{2}+\left(\frac{y-y_{\operatorname{cog}}}{b}\right)^{2}}
$$

where $a$ and $b$ are the real dimensions of the specimen cross section, and $x_{\operatorname{cog}}$ and $y_{\operatorname{cog}}$ are the values of the specimen center of gravity. The coefficient $l$ can take values between 0 and $\sqrt{2}$.

In the case that the specimen has all its pores uniformly distributed, the histogram of $l$ distribution presents a specific geometry (Figure 7).

In real specimens, the histogram of $l$ distribution shows a different shape (Figures 8 and 9). Depending on the shape of the histogram and how much it differs from the theoretical histogram, we can obtain an idea of what the pore distribution inside the specimen is like.

Figure 8 shows how there are hardly any differences in pore distribution between specimens. The small differences are due to the intrinsic dispersion of the concrete, which results in a non-identical distribution of pores within the matrix.

However, the average distribution histogram is almost coincident with the theoretical value corresponding to a uniform distribution. This means that, at a larger scale, this intrinsic dispersion disappears. The fact that the specimens have been cut from the inside of a prism means that the edge effect does not exist. 


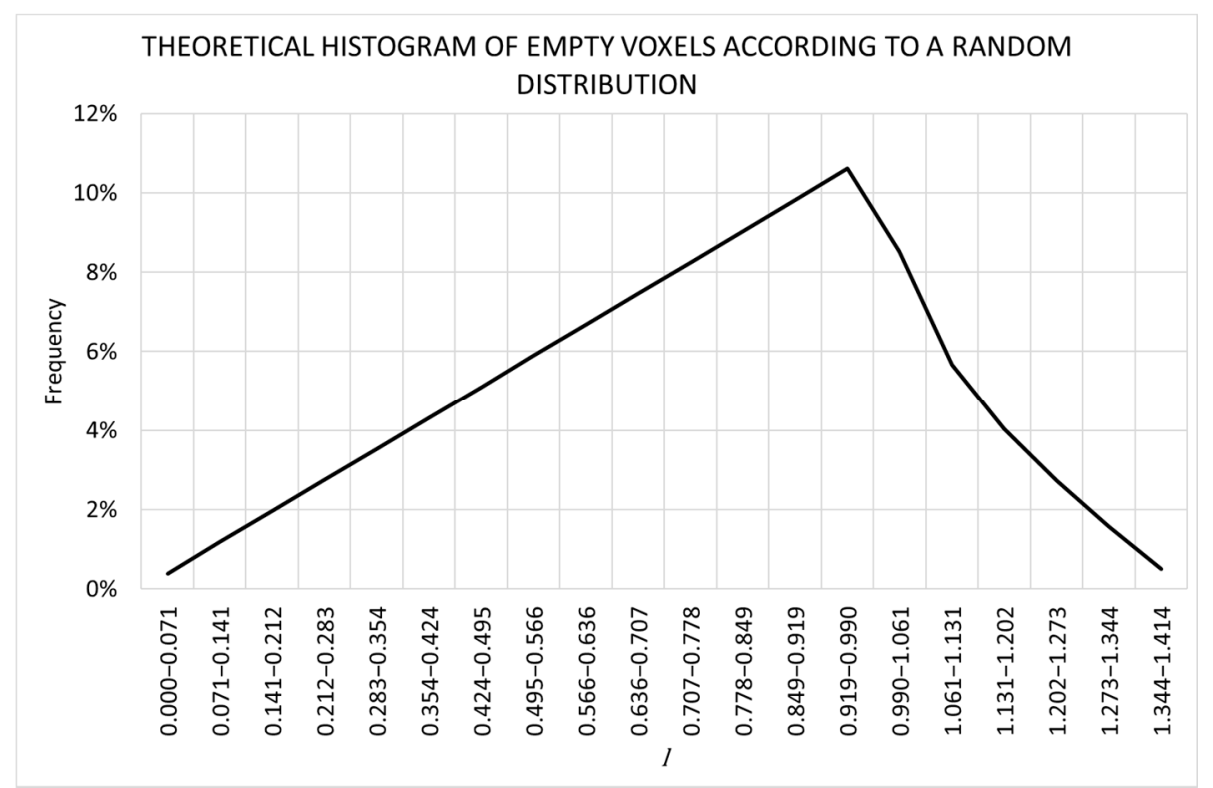

Figure 7. Circumferential test. Theoretical histogram of empty voxels according to a random distribution.

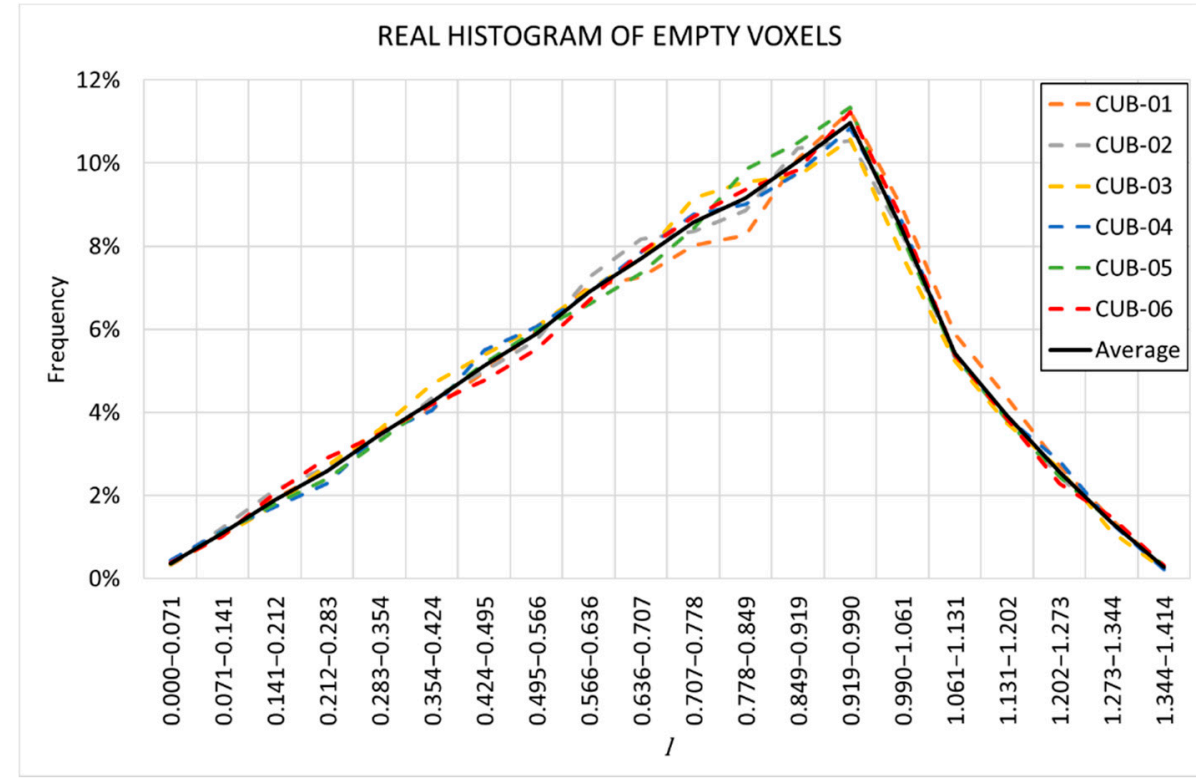

Figure 8. Circumferential test. Real histogram of empty voxels.

In this example, all the pores of the specimens have been analyzed. In certain situations, it may be interesting to evaluate a fraction of the pores (for example, those above or below a certain critical size). It is also possible to evaluate only the pores located in a region of the specimen (to study, for example, if there is segregation). In all these cases, the process for obtaining these partial histograms is simple, since it is enough to filter out the pores that meet the required conditions. 


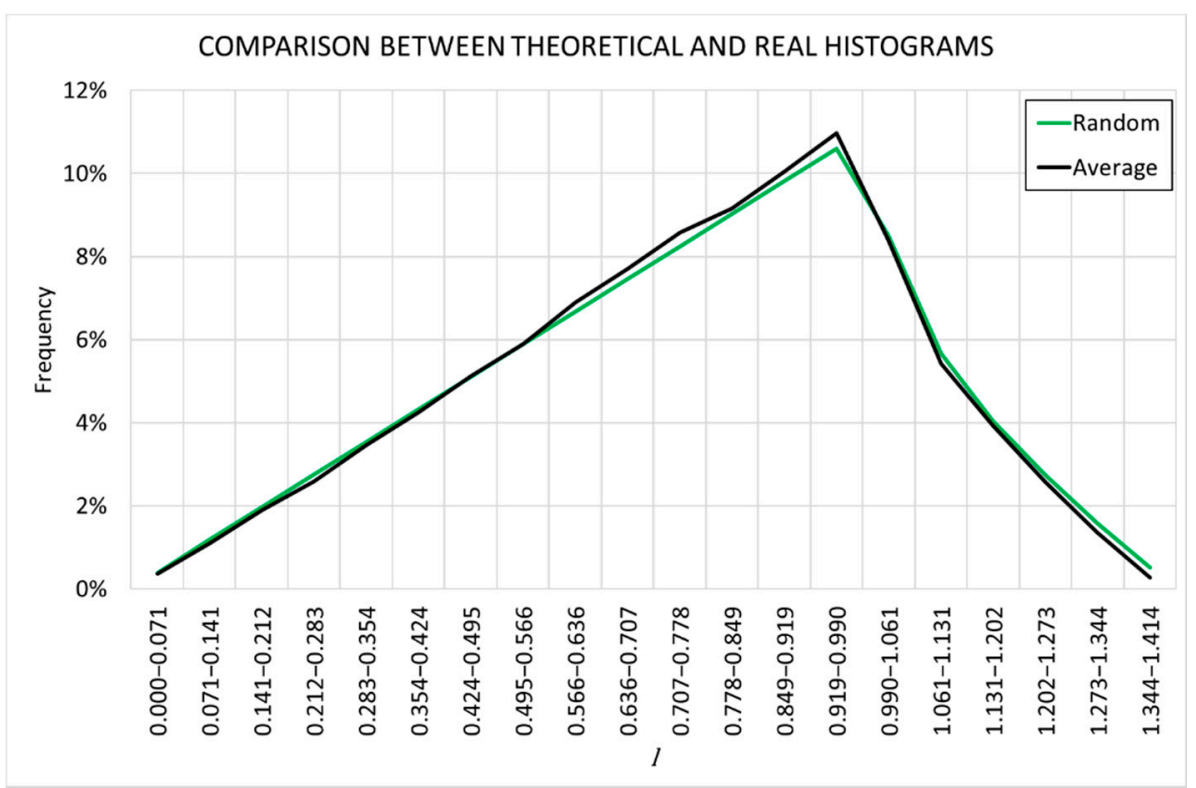

Figure 9. Circumferential test. Comparison between real and theoretical histograms.

\subsection{Radial Test}

The radial test is a variant of the circumferential test, in which the position of the center of gravity of the pore is replaced by the angle formed, with respect to the $\mathrm{X}$ axis, by the line that joins it with an axis parallel to the vertical $\mathrm{Z}$ axis passing through the center of gravity of the specimen.

Analogous to the circumferential test, the pore position is replaced by a numerical value $\alpha$, which corresponds to the angle obtained according to the following expression (Equation (3)):

$$
\alpha=\tan ^{-1} \frac{\left(\frac{y-y_{\operatorname{cog}}}{b}\right)}{\left(\frac{x-x_{\operatorname{cog}}}{a}\right)}
$$

In this case, the coefficient $\alpha$ can take values between 0 and 360 .

Again, if all pores are uniformly distributed, the histogram of $\alpha$ distribution presents a specific geometry (Figure 10).

The four peaks observed in the theoretical histogram correspond to the four semidiagonals of the specimen section.

In real specimens, the histogram of $\alpha$ distribution is different (Figures 11 and 12), which helps us to understand how the characterization of the pore distribution inside the specimen.

Figure 11 shows how, in this case, there is a certain dispersion in the pore distribution, clearly higher than that of the circumferential test. In particular, specimen CUB-06 shows a distribution markedly different from the rest, with a pore concentration above average between approximately the first and second valley (i.e., in the range $60<\alpha<200$ ). In the rest of the domain, the curve is below average. This shows that this specimen has a pore bias in a particular region.

Moreover, the average histogram is similar to the theoretical value, although, unlike the circumferential test, certain differences can be observed here. There are regions where the porosity is lower than expected while in others it is slightly higher. 


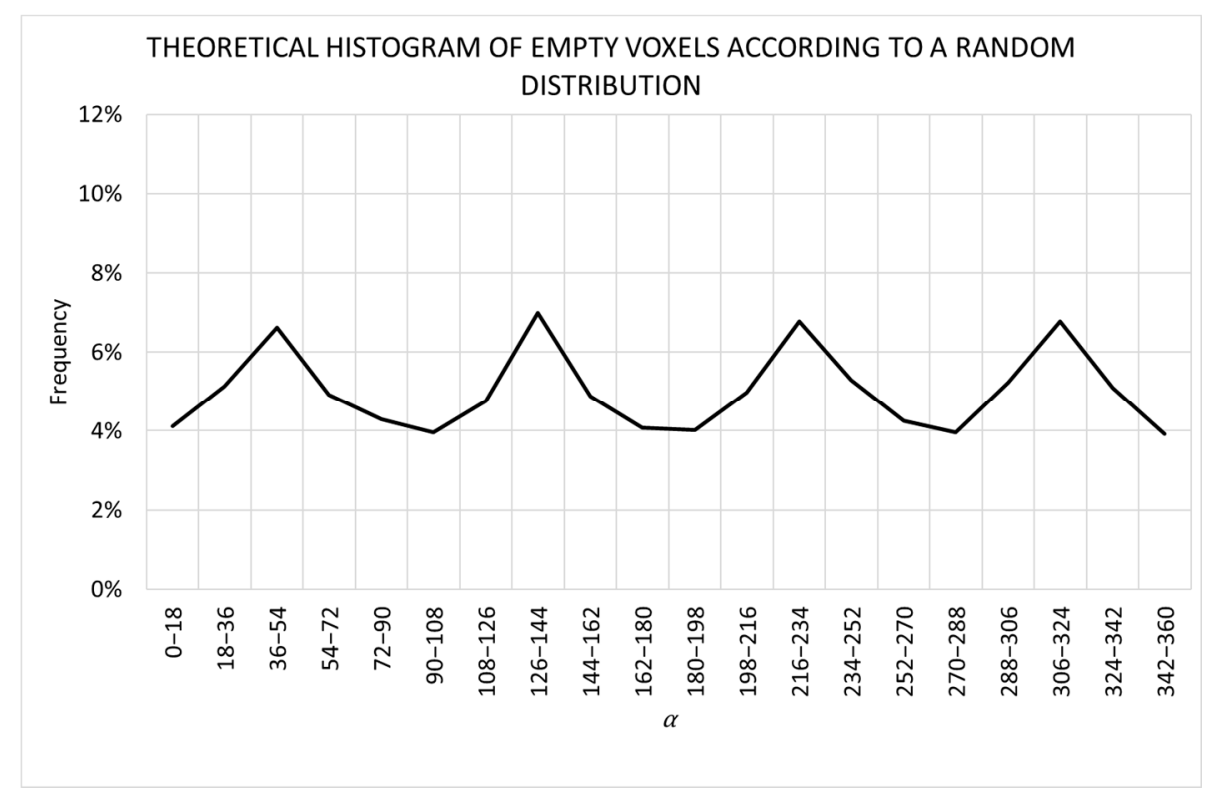

Figure 10. Radial test. Theoretical histogram of empty voxels according to a random distribution.

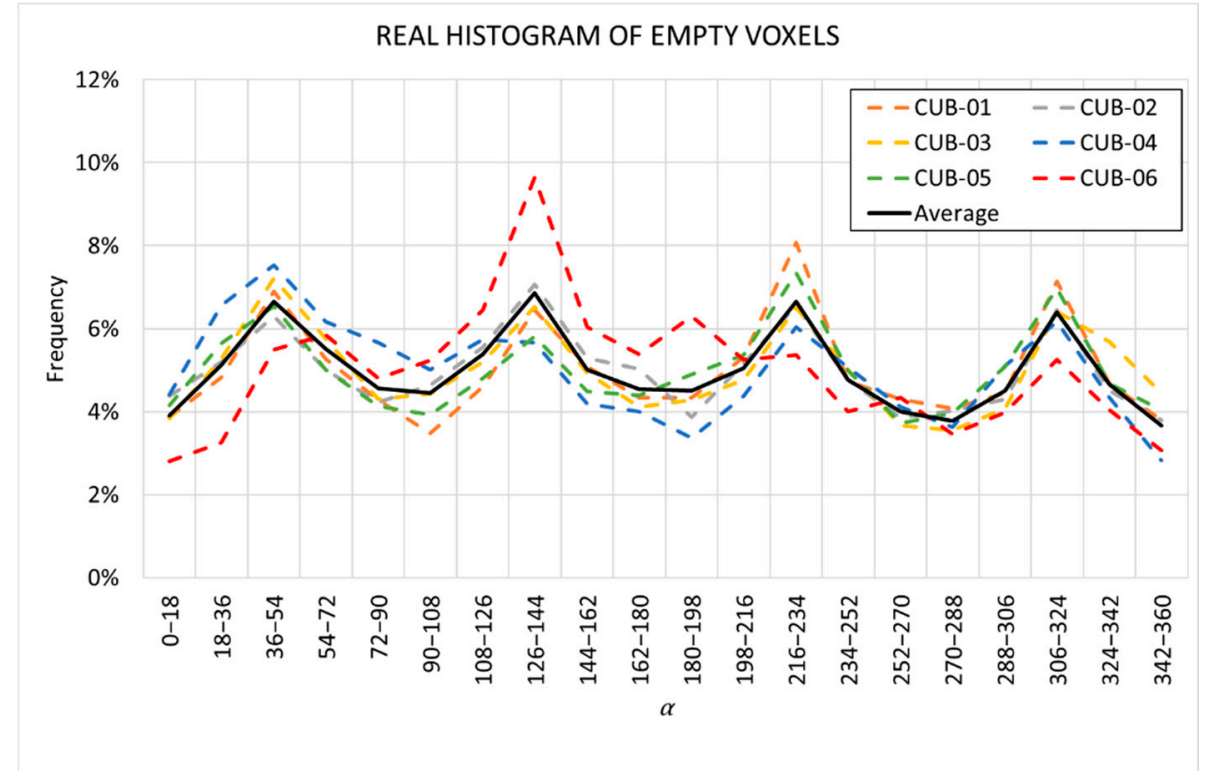

Figure 11. Radial test. Real histogram of empty voxels.

As in the previous case, filters can be applied to the information obtained from the CT-Scan to work with subsets of pores. This can be useful to know if, for example, there is some kind of wall effect depending on the pore size. In addition, the vertical test can also be applied to damaged specimens to check if the cracking distribution is uniform or if there are certain directions of the specimen that show planes of weakness. 


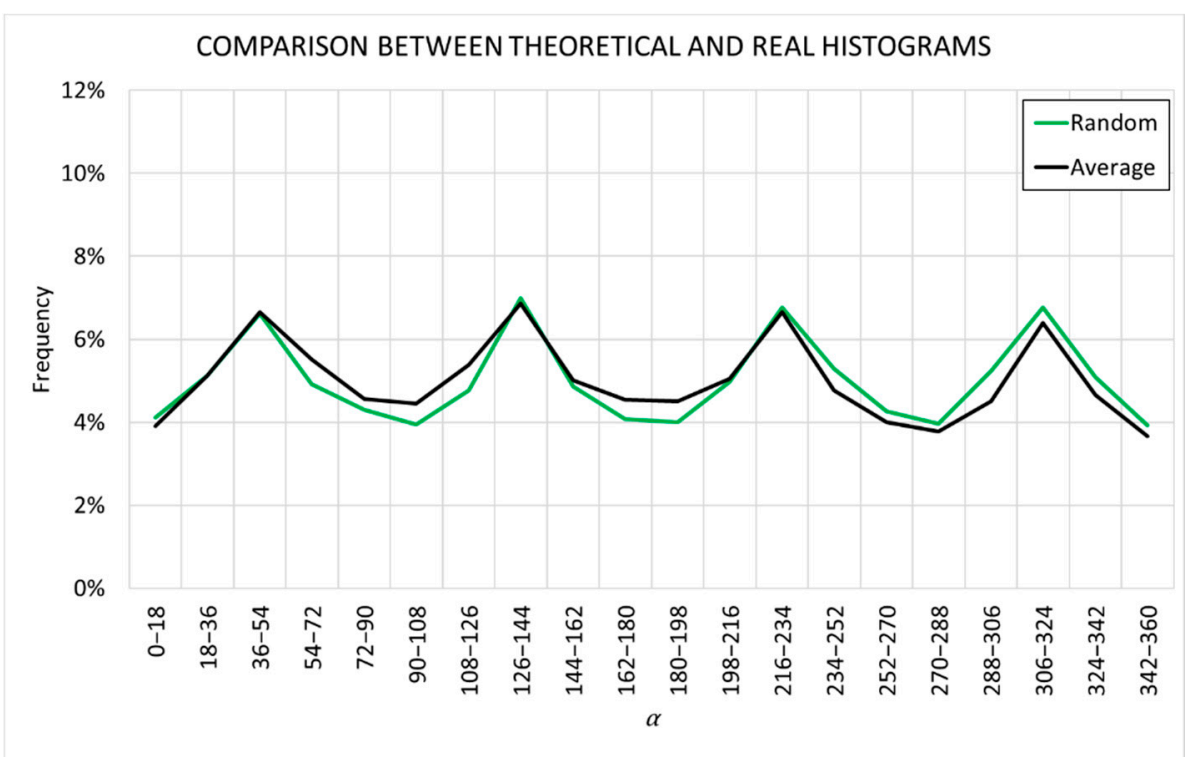

Figure 12. Radial test. Comparison between real and theoretical histograms.

\subsection{Vertical Test}

The vertical test is a variant of the two previous ones, in which the position of the center of gravity of the pore is replaced by its $Z$ coordinate. As in the case of the circumferential test, the $Z$ coordinate is made dimensionless by defining the coefficient $z$, which is obtained according to the following expression (Equation (4)):

$$
z=\frac{Z}{h}
$$

where $h$ is the height of the specimen. The coefficient $z$ can take values between zero and one.

When the pores are uniformly distributed, the histogram of $z$ distribution is a horizontal line (Figure 13). In real specimens this histogram is different (Figures 14 and 15).

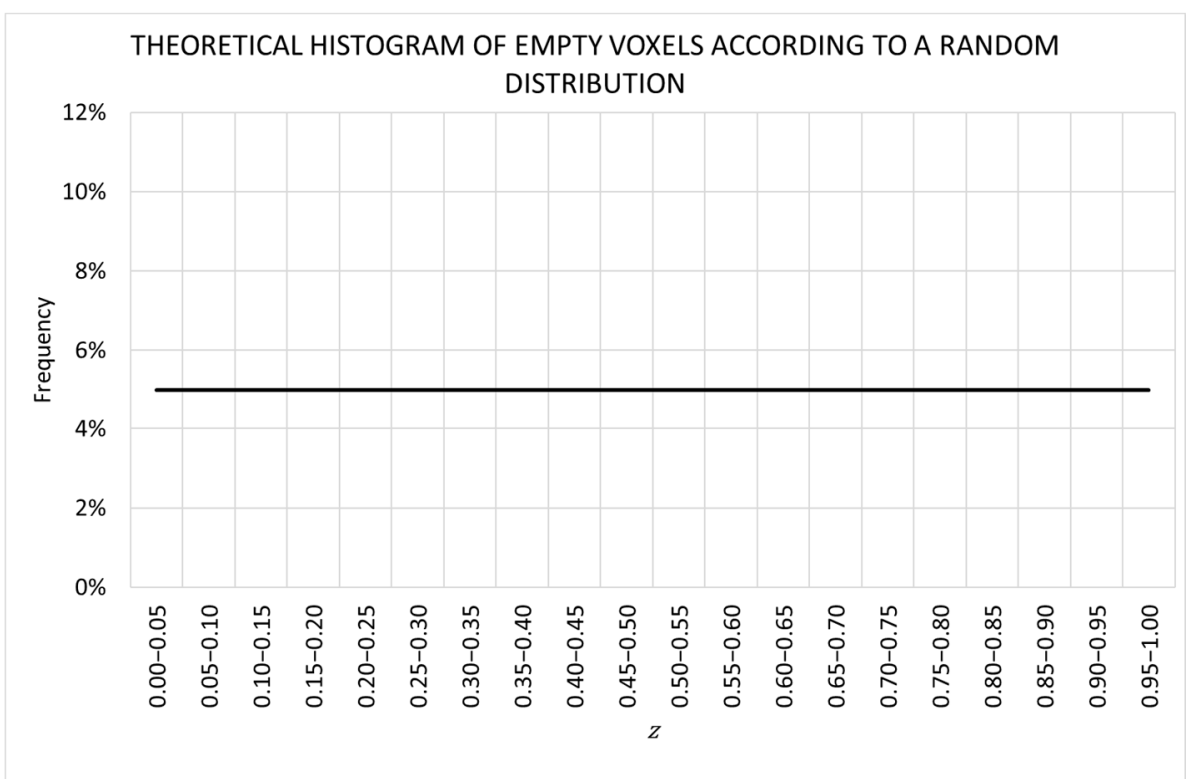

Figure 13. Vertical test. Theoretical histogram of empty voxels according to a random distribution. 


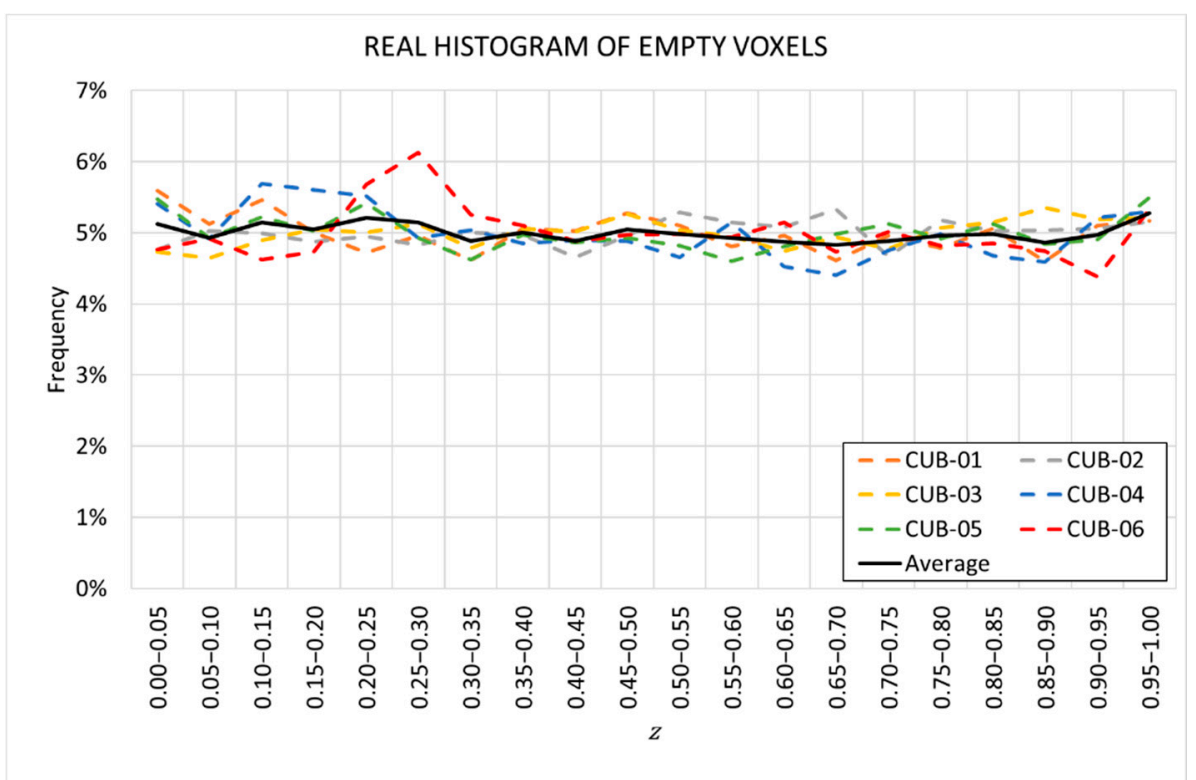

Figure 14. Vertical test. Real histogram of empty voxels.

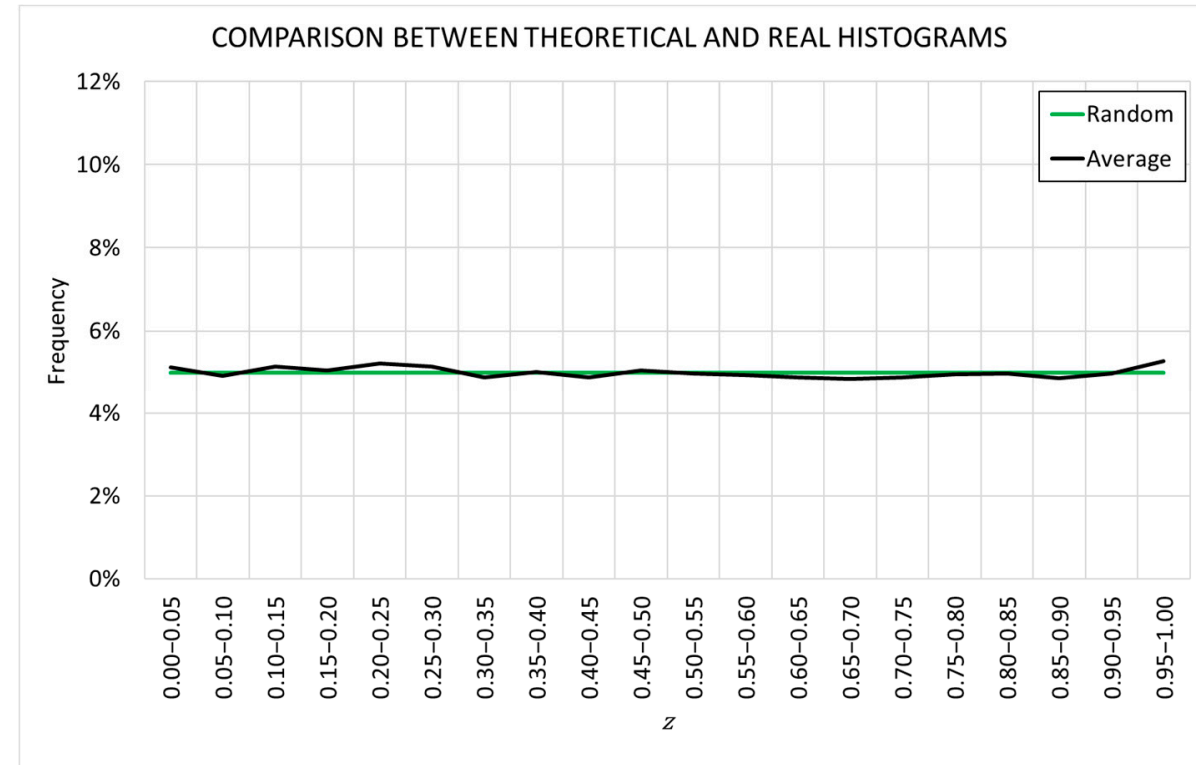

Figure 15. Vertical test. Comparison between real and theoretical histograms.

Figure 14 shows how, in this case, there is dispersion in the pore distribution. In particular, specimens CUB-04 and CUB-06 show a higher percentage of pores in the lower region. Specimen CUB-04 presents more pores in the range $0.1<z<0.3$, and specimen CUB-06 in the range $0.2<z<0.4$.

On the other hand, the average histogram is almost coincident with the theoretical value.

The vertical test can be very useful to detect aggregate segregation in concrete. When this occurs, the aggregates precipitate to the bottom of the specimen, while the grout remains at the top. As a result, the concrete matrix along the specimen is not uniform, and so are the porosity patterns. 


\subsection{Neighborhood Test}

The neighborhood test consists, in essence, of assigning to each pore a numerical value $d$ that corresponds to its distance to the nearest pore. This value depends not only on the size of the specimen but also on the number of pores.

In case the pores are evenly distributed in the specimen, the distance to the nearest pore would be equal in all pores and its value can be obtained according to the following expression (Equation (5)):

$$
n=\frac{1}{6} \cdot\left(\frac{\sqrt{2} \cdot \sqrt[3]{3} \cdot \sqrt[3]{V}}{d}\right) \cdot\left(\frac{\sqrt{2} \cdot \sqrt[3]{3} \cdot \sqrt[3]{V}}{d}+1\right) \cdot\left(\frac{\sqrt{2} \cdot \sqrt[3]{3} \cdot \sqrt[3]{V}}{d}+2\right)
$$

where $n$ is the number of pores, $V$ is the volume of the specimen and $d$ is the distance to the nearest pore.

This expression was obtained considering an analogy of the hexagonal close-packing of spheres.

As mentioned, if the pores were uniformly distributed, all pores would show the same distance value to the nearest pore. However, in real specimens, each pore shows a different distance value. Figure 16 shows the histograms of the nearest pore distance distribution for each of the specimens, as well as its theoretical value corresponding to a uniform pore distribution.

The results reveal that the pores are non-uniformly distributed in the specimens. There are regions (which this test is not able to identify) where they are closer together and others where they are farther apart.

In this case study, the distribution closely resembles a uniform distribution. In the majority of the specimens, the most frequent value coincides with the theoretical value. Only in specimens CUB-01 and CUB-04 is the most frequent value lower than the theoretical value.

From the data shown by the histogram it is possible to determine the "pore concentration factor" $p c f$, according to the following expression (Equation (6)):

$$
p c f=\sum_{i=1}^{n} f_{i} \cdot \frac{d_{T}-\bar{d}_{i}}{d_{T}}
$$

where $d_{T}$ is the theoretical distance, $\bar{d}_{i}$ is the mean value of each range of distances in the real histogram, $f_{i}$ is its frequency and $n$ is the number of bars in the histogram.

The pore concentration factor takes values between zero and one, with zero being when the pores are uniformly distributed throughout the specimen and one being when the pores are fully concentrated. The values of the pore concentration factors of the specimens in this study are shown below (Table 2):

Table 2. Pore concentration factors.

\begin{tabular}{ccccccc}
\hline Specimen & CUB-01 & CUB-02 & CUB-03 & CUB-04 & CUB-05 & CUB-06 \\
\hline $\begin{array}{c}\text { Pore Concentration } \\
\text { Factor }\end{array}$ & 0.024 & 0.008 & 0.008 & 0.037 & 0.014 & 0.031 \\
\hline
\end{tabular}

The results show that there are three specimens (CUB-02, CUB-03 and CUB-05) in which the pores are quite evenly distributed. In the rest of the specimens the distribution is far from uniform.

The neighborhood test can be applied to correlate porosity distribution with concrete failure mechanisms. For example, it can be tested whether pore concentrations act as preferential pathways for cracks, and consequently specimens with a higher $p c f$ have lower strength. 


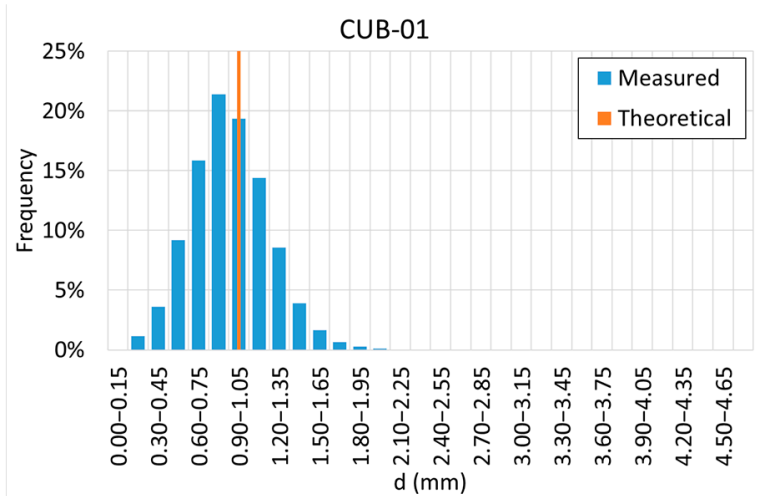

(a)

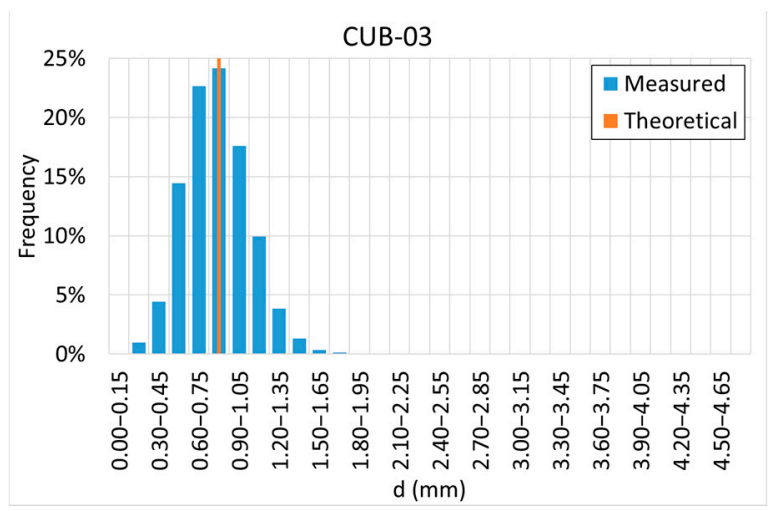

(c)

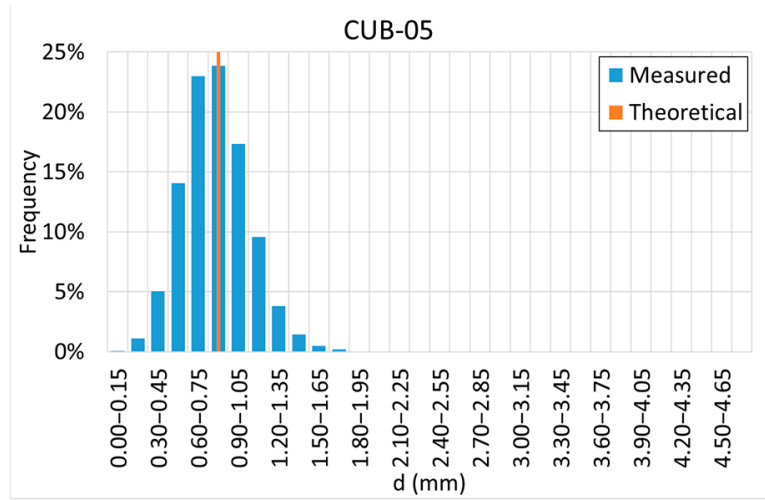

(e)

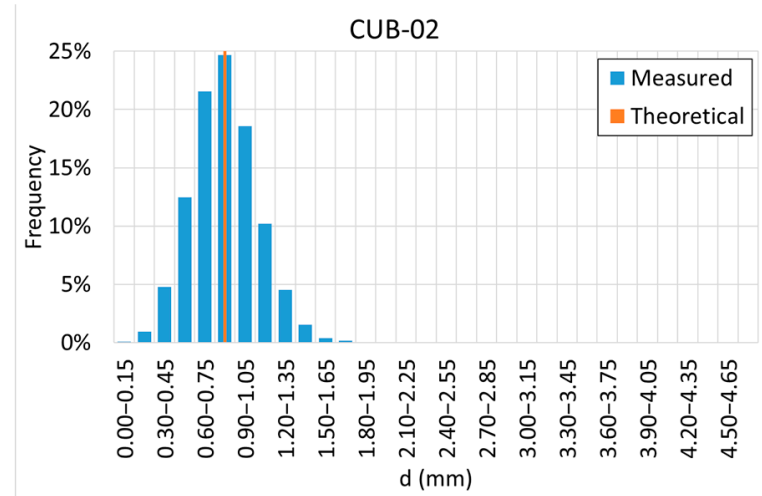

(b)

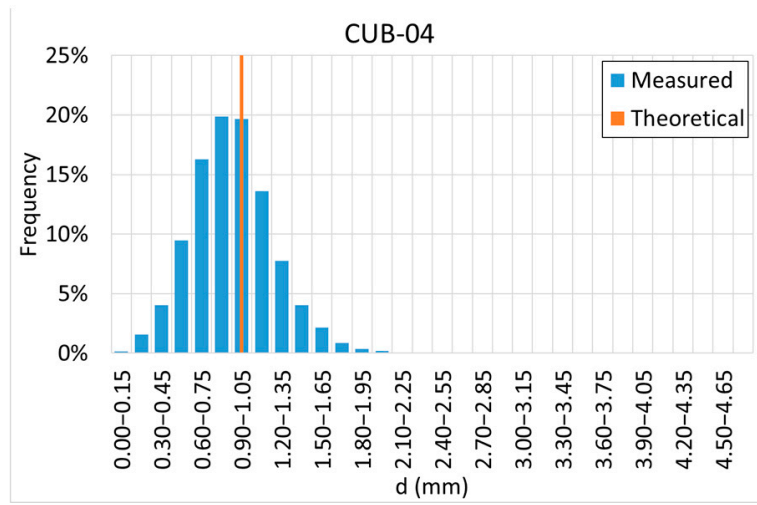

(d)

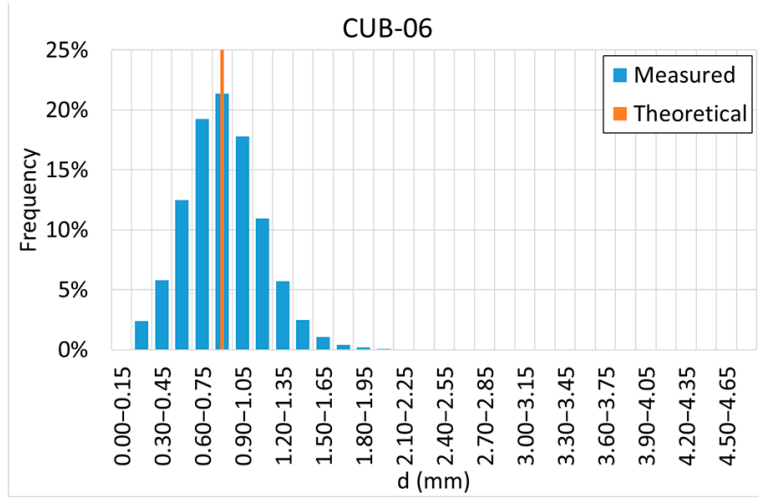

(f)

Figure 16. Neighborhood test. Comparison between real and theoretical histograms. From (a-f) specimens 1 to 6.

\subsection{Pore Size Distribution: Porosity Curves and Cumulative Pore-Volume Curves}

Two types of curves can be used to evaluate the pore size distribution, namely the porosity curve and the cumulative pore-volume curve.

The first one represents, for each pore length, the volume of pores with a length equal to or less than it. The value of the pore volume can be expressed either in absolute terms (i.e., $\mathrm{mm}^{3}$ of pores) or in relative terms, by dividing the total volume by the volume of the specimen. This last option is more interesting, as it allows comparison of porosities between specimens of different sizes.

The second one represents, for each pore length, the percentage of the total pore volume that has a length equal to or less than this one.

In both cases, as a previous step to the graphical representation of the data, we need to collect all the pores and order them from the shortest to the longest length. 
Figure 17 illustrates that the specimens show different porosity values. Some specimens (such as CUB-06) show particularly high overall porosity values while others (such as CUB-02) have clearly lower values. In addition, the curve reveals that some specimens (such as CUB-01, CUB-04 and CUB-06) show some very large pores (more than $10 \mathrm{~mm}$ in the case of CUB-06).

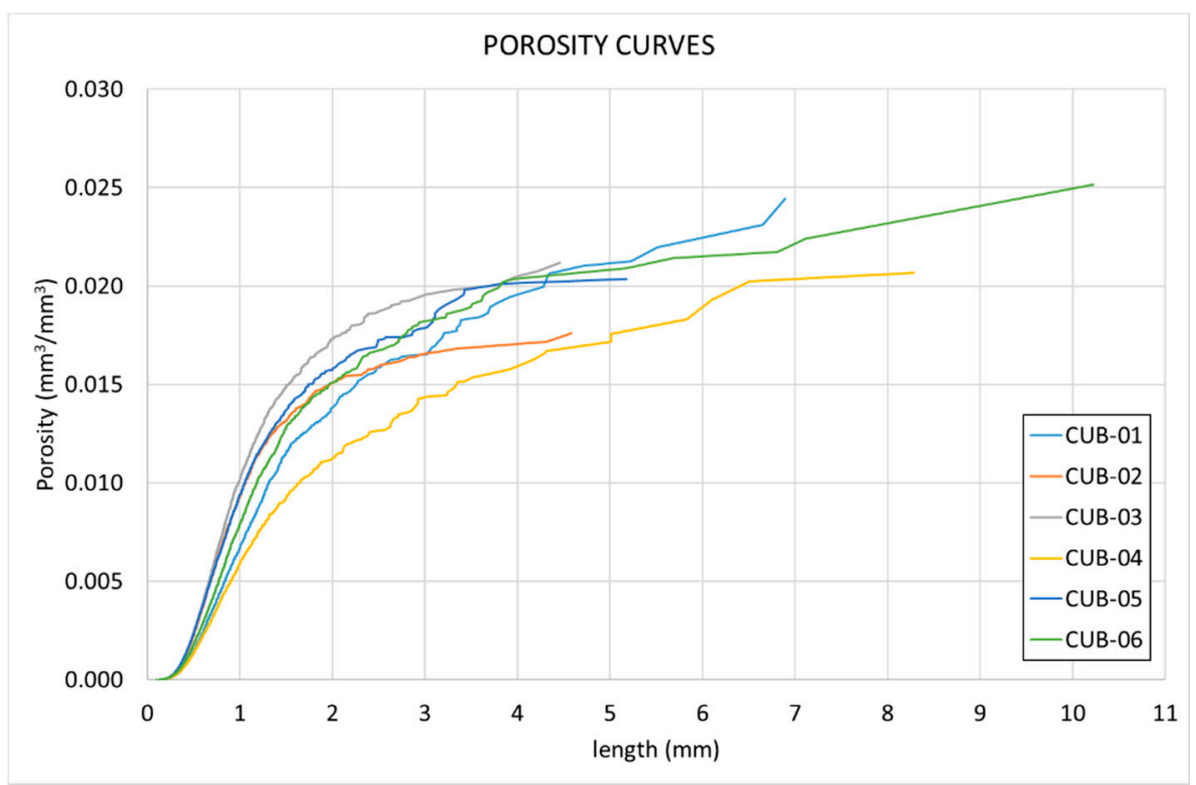

Figure 17. Porosity curves.

Figure 18 reveals that the specimens are divided into two groups. On the one hand, specimens CUB-02, CUB-03 and CUB-05 show a much steeper curve, which indicates that their porosity is smaller; that is, the percentage of small pores is clearly higher. On the other hand, the other three specimens show a smoother curve, which means that they have a higher percentage of larger pores.

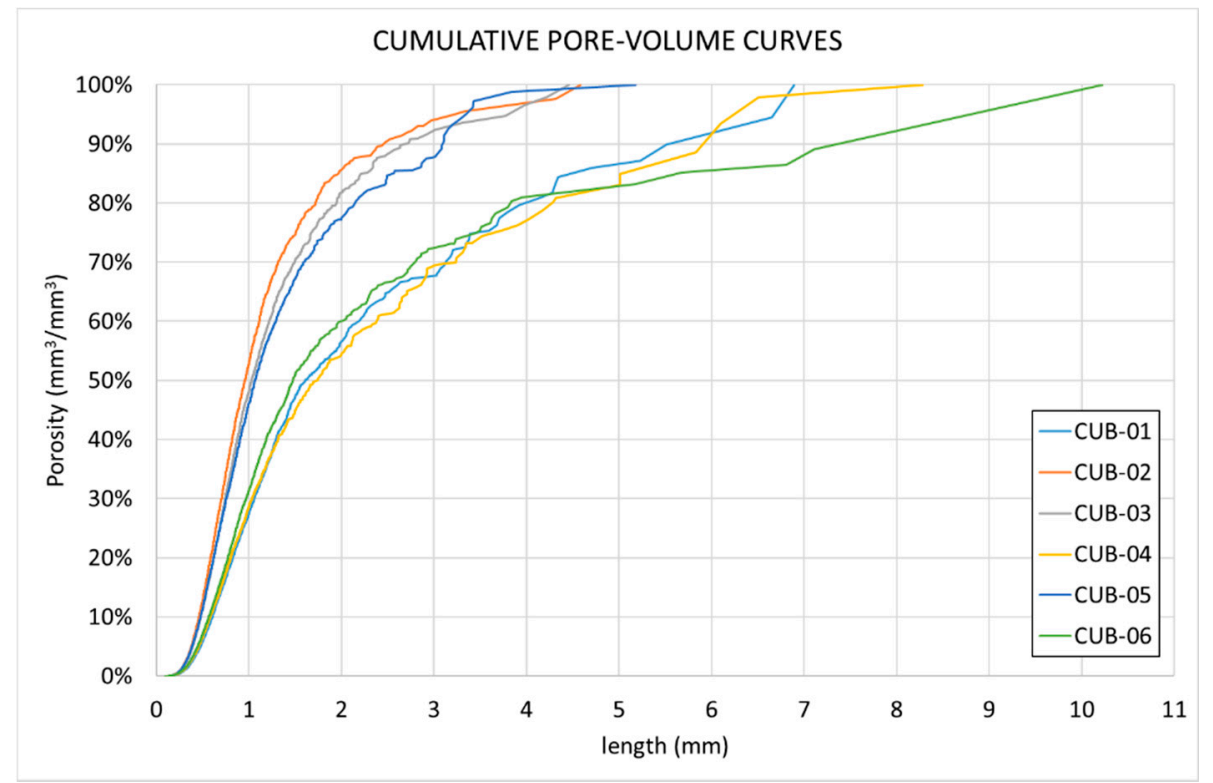

Figure 18. Cumulative pore-volume curves.

From the data of the cumulative pore-volume curve, it is possible to define the parameter "maximum pore size" which, by analogy with the maximum aggregate size widely 
used in concrete, is defined as that pore length related to $90 \%$ of the total pore volume (Table 3).

Table 3. Maximum Pore Size.

\begin{tabular}{ccccccc}
\hline Specimen & CUB-01 & CUB-02 & CUB-03 & CUB-04 & CUB-05 & CUB-06 \\
\hline $\begin{array}{c}\text { Maximum Pore Size } \\
(\mathrm{mm})\end{array}$ & 5.51 & 2.48 & 2.73 & 5.96 & 3.09 & 7.11 \\
\hline
\end{tabular}

It is interesting to note that specimens showing a lower maximum pore size also show a smaller pore concentration factor, i.e., they have more evenly distributed pores.

The analysis of pore size distribution allows us to have an overall idea of the porosity of a specimen. This is especially interesting when we want to analyze the influence of components (fibers, fillers, etc.) or additives (air entraining agents, superplasticizers, etc.) on the concrete matrix. It should be noted that in many cases it is convenient to discard the larger pores (>approx. $5 \mathrm{~mm}$ ), since in many cases they represent a high percentage of the porosity volume, but do not have a significant macroscopic influence.

\subsection{Histograms of Pore Distribution}

The histograms of pore distribution represent, for each volume range, the number of pores whose volume is within that range. This information can be displayed in absolute values, i.e., the number of pores belonging to each volume range is shown on the ordinate axis, or in relative terms, representing the percentage of pores with respect to the total that belong to each volume range. This second option is more interesting when comparing patterns between different specimens.

In general, the highest percentage of pores corresponds to very small volumes; therefore, it is usually interesting to represent nested histograms, i.e., on a histogram representing $100 \%$ of the pores, histograms are successively generated in which certain ranges of volumes (generally the smallest ones) are observed in greater detail.

The results of the specimens considered in this work are shown below (Figure 19).

The results show that almost $100 \%$ of the pores have a volume of less than $1 \mathrm{~mm}^{3}$. If we analyze the data in more detail, we can notice that more than half of the pores have a size of less than $0.01 \mathrm{~mm}^{3}$, and between $15 \%$ and $20 \%$ of all pores are smaller than $0.001 \mathrm{~mm}^{3}$.

This reveals that it is highly interesting for CT-scan technology to advance towards better resolutions. In this way it will be possible to analyze smaller and smaller pores, which are precisely the most numerous and presumably have the greatest influence on the macroscopic behavior of concrete.

\subsection{Histograms of Pore-Volume Distribution}

As seen in the previous subsection, small pores are dominant in number, but represent a less important volume. Alternatively to the histograms shown in Figure 19, it is possible to obtain histograms of pore distribution according to pore volume. These represent, for each volume range, the total volume of those pores whose individual volume is within that range. Again, this information can be displayed in absolute values or in relative values, i.e., showing for each volume range the percentage of the total volume.

Similar to the previous case, it is often interesting to represent nested histograms. The results of the specimens considered in this work are shown below (Figure 20). 


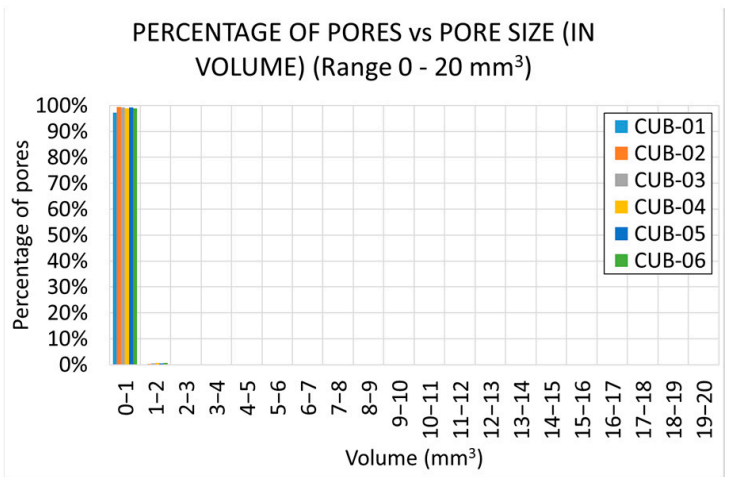

(a)

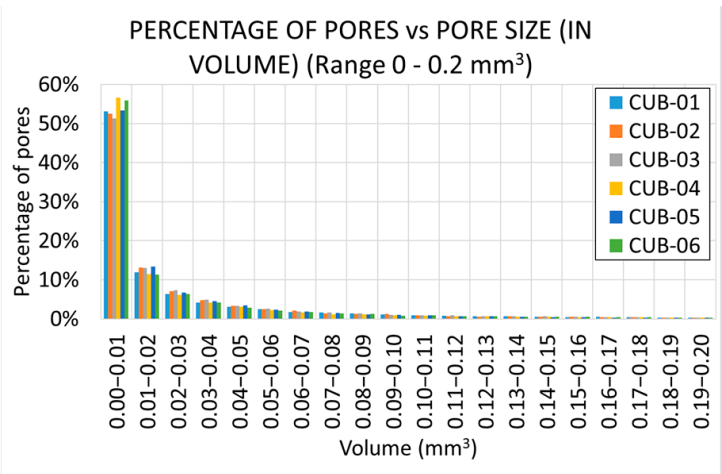

(c)

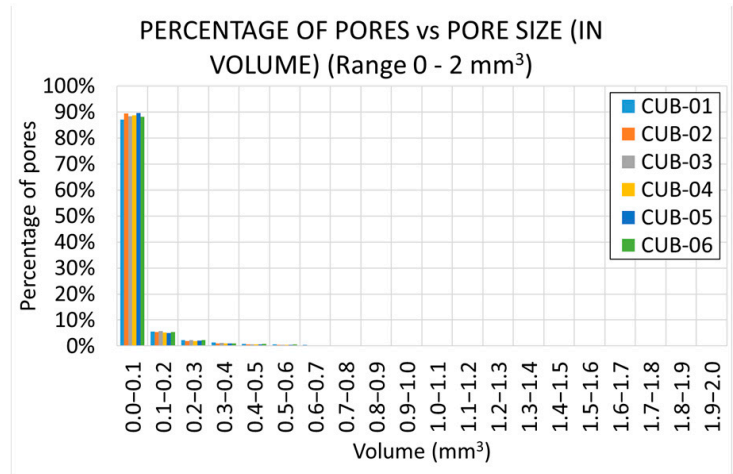

(b)

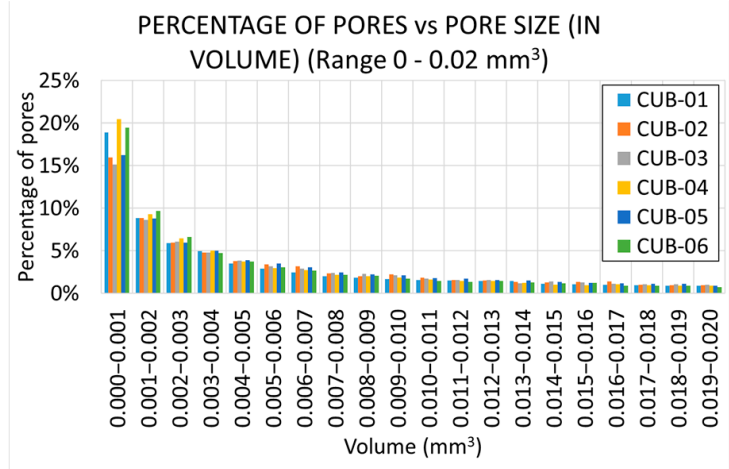

(d)

Figure 19. Histograms of pore distribution (in volume) for different ranges, from the largest to the smallest (a-d).

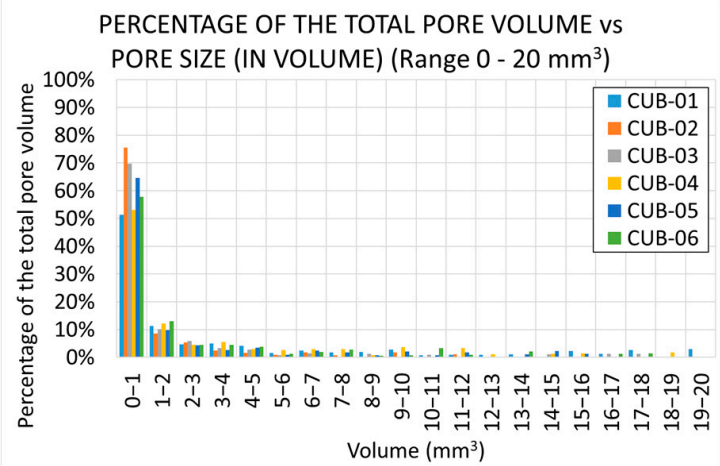

(a)

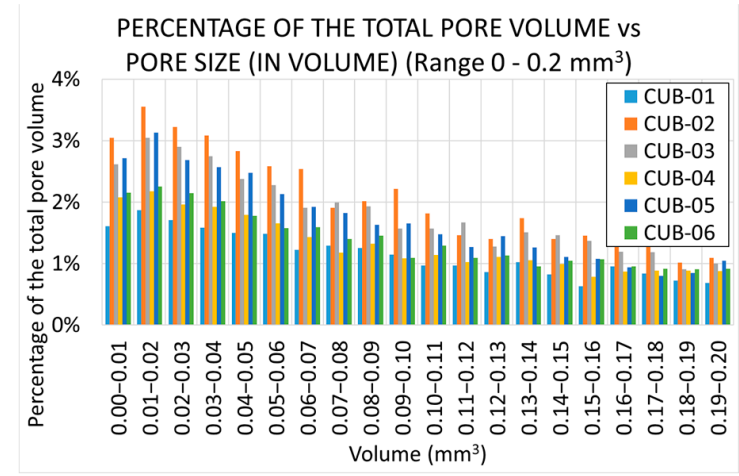

(c)

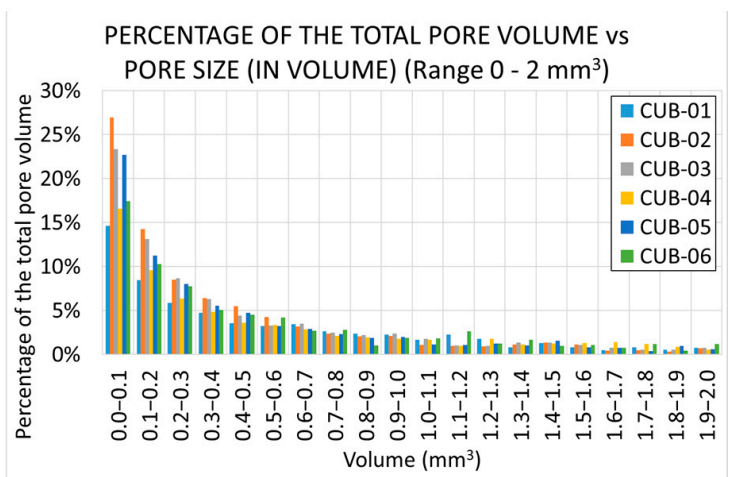

(b)

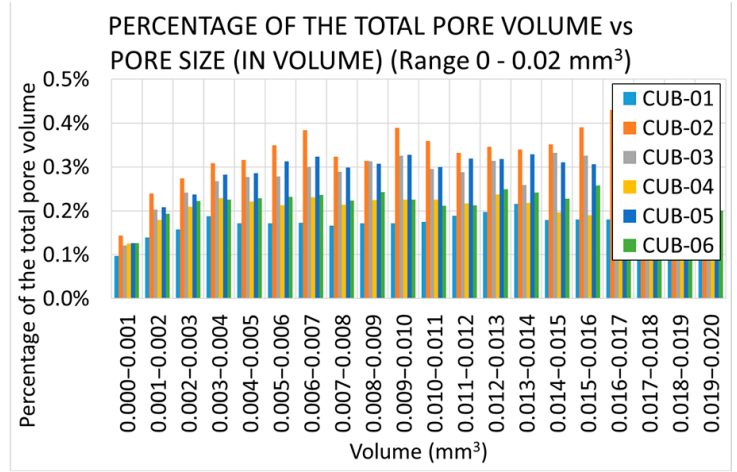

(d)

Figure 20. Histograms of pore-volume distribution (in volume) for different ranges, from the largest to the smallest (a-d). 
The results reveal some interesting points. Again, most of the total porosity of the specimens is distributed in pores less than $1 \mathrm{~mm}^{3}$. However, significant differences are observed between specimens, varying from 50\% to $75 \%$. While Figure 17 shows that almost $100 \%$ of the pores are less than $1 \mathrm{~mm}^{3}$, this represents "only" between $50 \%$ and $75 \%$ of the total porosity.

In a more detailed analysis, we observe that most of the total porosity belongs to pores smaller than $0.1 \mathrm{~mm}^{3}$, with many differences between specimens (from $15 \%$ to $27 \%$ ). Comparing Figure 20 with Figure 19, we can see that the pores smaller than $0.1 \mathrm{~mm}^{3}$, which represent approximately $90 \%$ of the total pores, only contain between $15 \%$ and $27 \%$ of the total porosity.

These morphological analyses can be of great interest to understand the intrinsic dispersion associated with the mechanical response of the specimens. It is expected that these specimens show different behavior against certain external actions (for example, different response against freeze-thaw cycles, or different behavior against mechanical or thermal fatigue) and that this can be explained by the different morphology of their microstructure.

\subsection{Histograms of Pore Distribution and Pore-Volume Distribution (In Length)}

As an alternative to the two previous subsections, it is possible to classify pores according to their length instead of their volume. In this way, firstly, histograms of pore distribution (in length) and, secondly, histograms of pore-volume distribution (in length) can be obtained.

In the first case, the histograms of pore distribution represent, for each length range, the number of pores whose length is within that range. Analogous to the previous case, it is often interesting to represent nested histograms. The histograms of the specimens considered in this work are shown below (Figure 21).

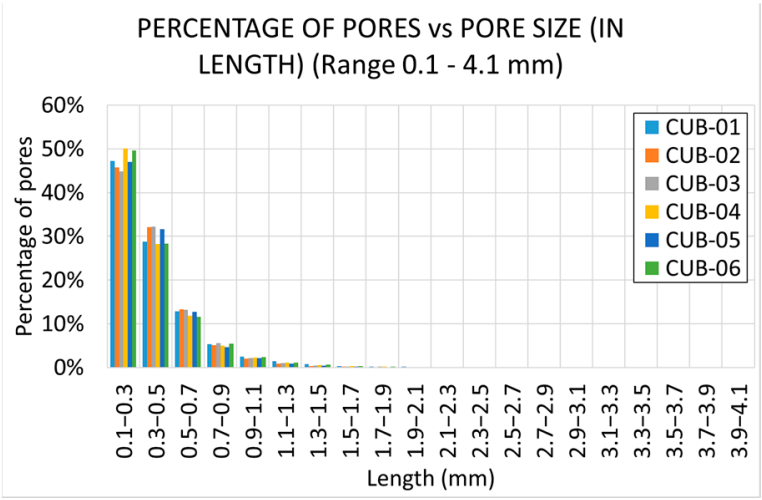

(a)

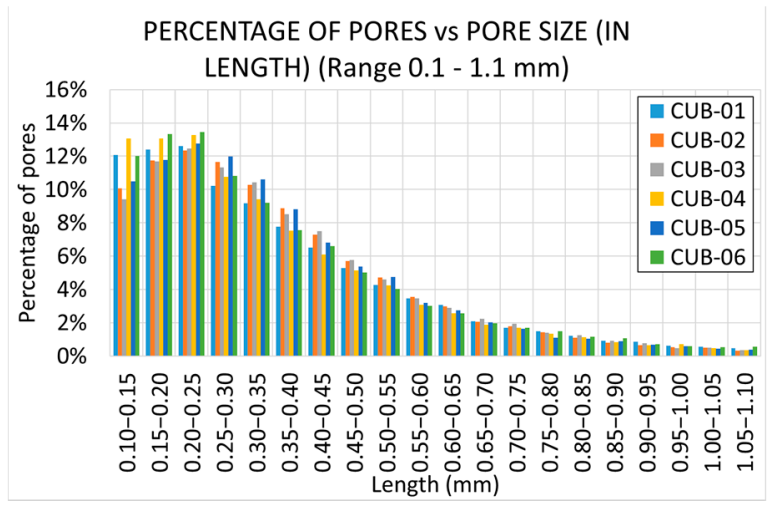

(b)

Figure 21. Histograms of pore distribution (in length) for different ranges, from the largest (a) to the smallest (b).

The results show that smaller pores are again predominant. In this case, about $50 \%$ of all pores have a length between 0.1 and $0.3 \mathrm{~mm}$. In a more in-depth analysis, it is observed that the most common length is in the range of 0.20 to $0.25 \mathrm{~mm}$. Differences are observed among the specimens, although they do not seem to be very significant.

It should be recalled that, due to the limitations of the scanning equipment, all those pores with a length of less than $0.1 \mathrm{~mm}$ were discarded.

In the second case, the histograms of pore-volume distribution (depending on pore length) represent, for each length range, the total volume of those pores whose length is within that range (Figure 22). 


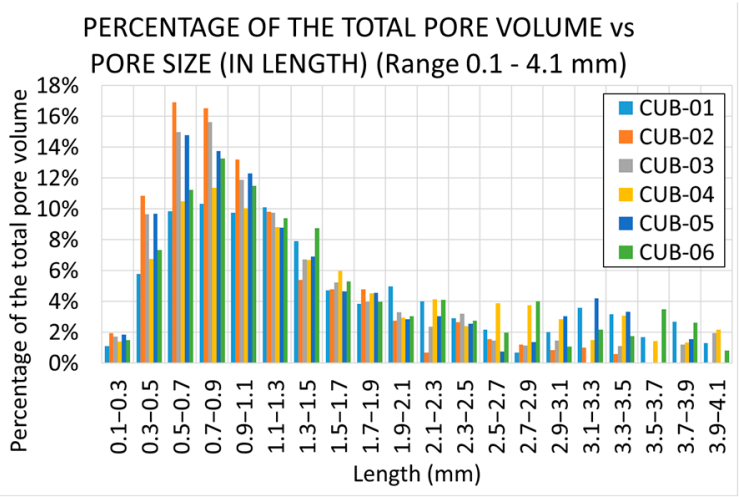

(a)

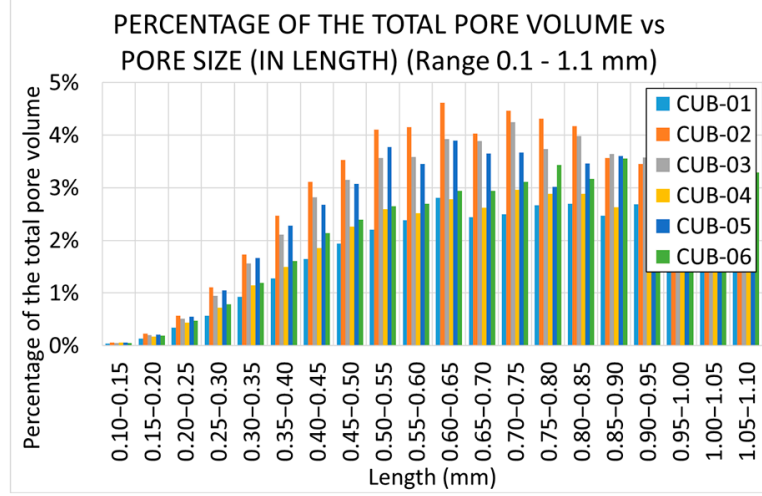

(b)

Figure 22. Histograms of pore-volume distribution (in length).

As can be seen in Figure 21, the largest percentage of the porosity of the specimens is in the pores whose length ranges from 0.7 to $0.9 \mathrm{~mm}$. Although this range of pores is not the most numerous, it is the one with the largest volume. In this case, a greater dispersion of results is observed among the specimens.

Again, the aim of these analyses is to know as precisely as possible the concrete microstructure, in order to try to explain the dispersion observed in macroscopic tests. This aspect is very interesting for the study of mechanical fatigue in concrete, whose intrinsic dispersion is very wide.

\subsection{Pore Shape: Sphericity Factor and Shape Factor}

Two parameters can be used to study pore shape, namely, sphericity factor and shape factor. The sphericity factor is defined as the ratio between the pore volume and the product of its area times its length, according to the following equation (Equation (7)):

$$
s p f=\frac{V}{A_{p} \cdot d_{p}}
$$

where $V$ is the pore volume, $A_{p}$ is the pore surface area and $d_{p}$ is the pore length. The sphericity factor can take values between 0 and $1 / 6$.

On the other hand, the shape factor is defined as the ratio between the volume of the pore and the volume of the circumscribed sphere, according to the following equation (Equation (8)):

$$
s f=\frac{V}{\frac{1}{6} \cdot \pi \cdot d_{p}^{3}}
$$

where $V$ is the pore volume and $d_{p}$ is the pore length. The shape factor can take values between zero and one.

Both the sphericity factor and the shape factor are parameters that indicate the degree of roundness of the pores, where larger values correspond to pores closer to a sphere and smaller values to pores that are less round.

The histograms of sphericity factor and shape factor distribution of the specimens in this work are shown below (Figures 23 and 24). 


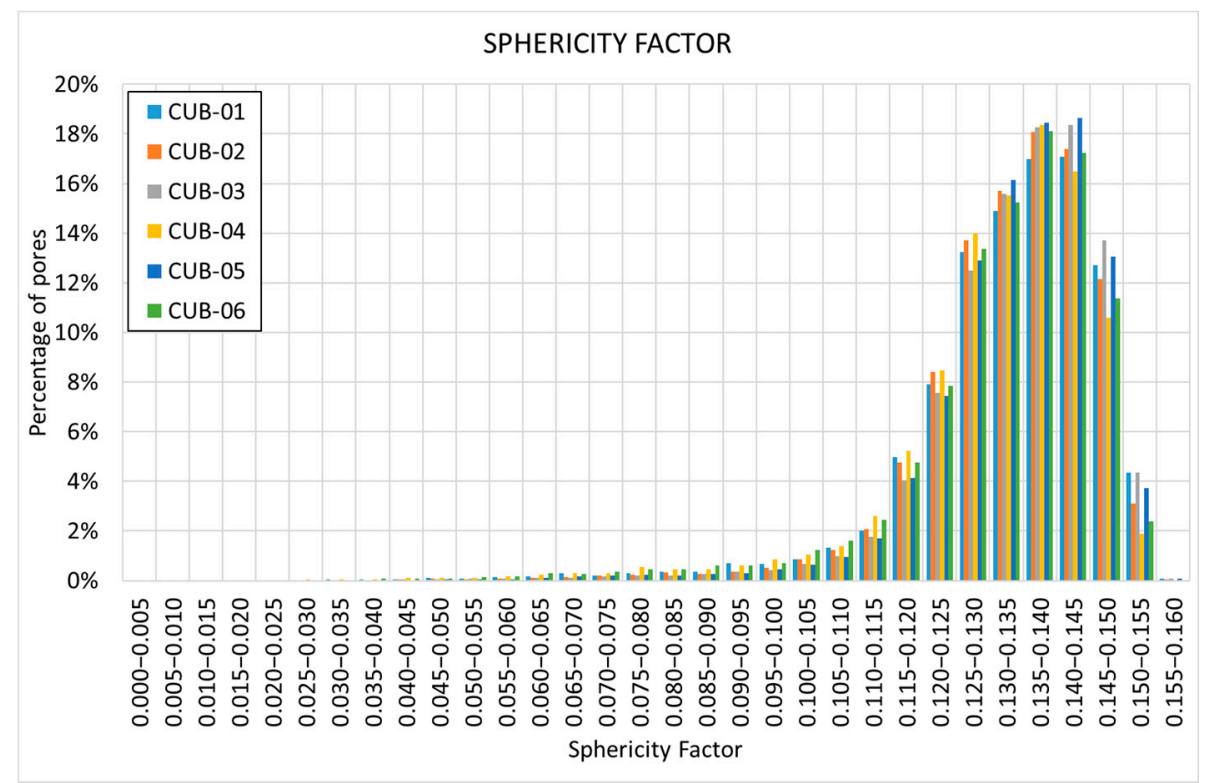

Figure 23. Histogram of the sphericity factor.

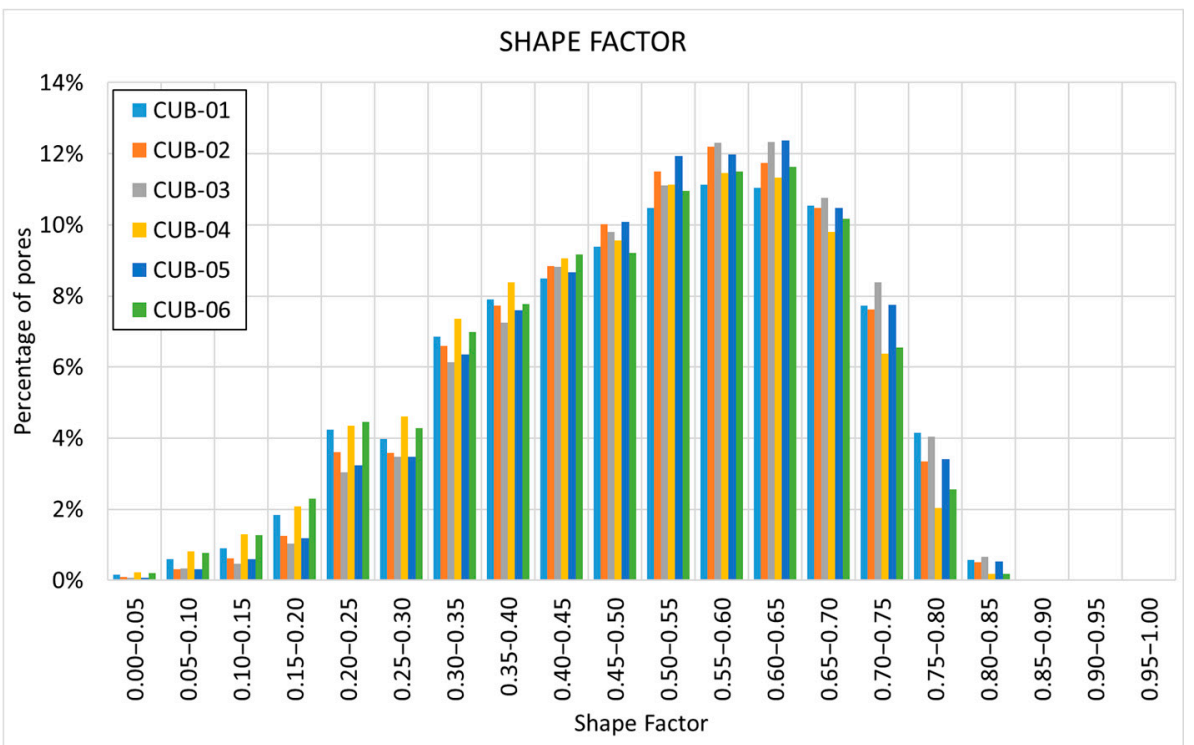

Figure 24. Histogram of the shape factor.

The results show some very interesting data. First, it can be observed that the pores are not spherical at all. The most common sphericity factor is in the range $0.135-0.14$ and the most usual shape factor is between 0.55 and 0.6. This is an important fact because almost all cracking mechanisms in concrete start with the birth of a crack from the pores. More elliptical pores are more likely to initiate a crack.

In this case, Figures 23 and 24 represent all pores. Based on the information obtained from the CT-scan, it is possible to plot histograms of the sphericity and shape factors for a certain range of sizes (e.g., for pores belonging to a given range of lengths or volumes). This can allow us to identify which pores may be more prone to crack initiation and propagation. In addition, the influence of components and additives on pore shape can also be analyzed using these parameters. 


\subsection{Pore Orientation}

As noted in the previous subsection, pores are not perfectly spherical. Therefore, it is possible to determine a principal axis and a principal length and, consequently, an orientation of this principal axis.

For each pore it is possible to determine the angles $\alpha, \beta$ and $\gamma$ (Figure 6). With the information from all the pores, histograms of orientation distribution can be obtained (Figure 25).

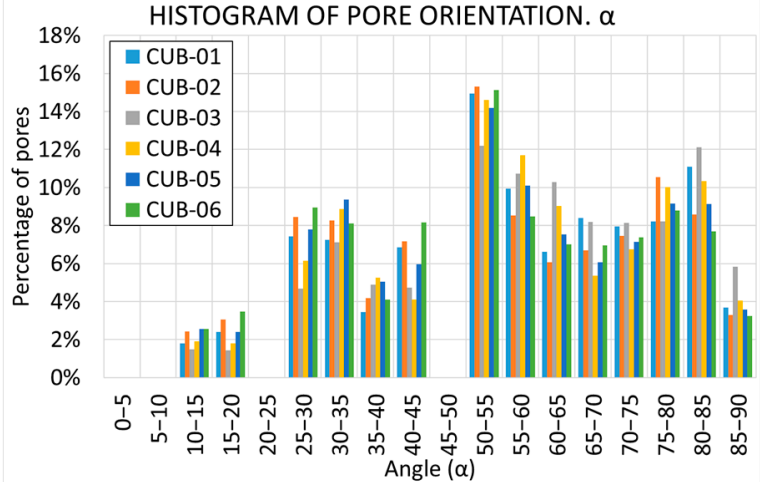

(a)

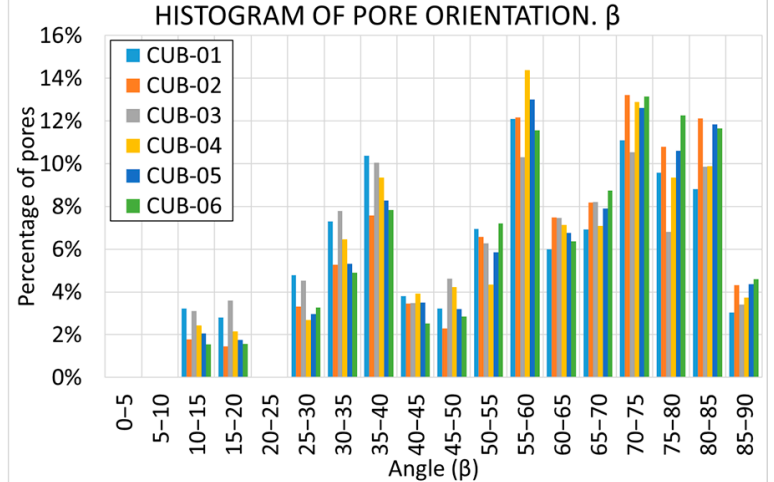

(b)

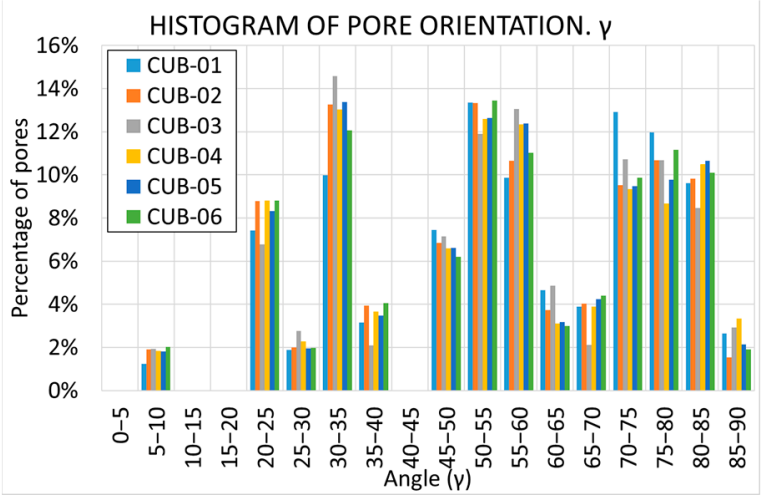

(c)

Figure 25. Histograms of pore orientation of the angles $\alpha,(\mathbf{a}) \beta$ (b) and $\gamma(\mathbf{c})$.

In this particular case, the pores show an approximately uniform orientation. These histograms can provide very useful information because they can detect a certain bias in pore orientation, which could indicate the presence of potential planes of structural weakness.

From the data provided by the histograms it is possible to determine the efficiency index, which can be defined according to the following expressions [1] (Equations (9)-(11)):

$$
\begin{aligned}
& e i_{x}=\sum_{i=1}^{n} f_{i} \cdot \cos ^{2} \overline{\alpha_{i}} \\
& e i_{y}=\sum_{i=1}^{n} f_{i} \cdot \cos ^{2} \overline{\beta_{i}} \\
& e i_{z}=\sum_{i=1}^{n} f_{i} \cdot \cos ^{2} \overline{\gamma_{i}}
\end{aligned}
$$

where $\overline{\alpha_{i}}, \overline{\beta_{i}}$ and $\overline{\gamma_{i}}$ are the mean values of each angular range, $f_{i}$ is the frequency associated with each angular range and $n$ is the number of bars in the histogram.

The efficiency index takes values between zero and one, being one when the pores are totally oriented with the corresponding axis and zero when the pores are arranged 
perpendicularly to it. The values of the efficiency indexes of the specimens in this study are shown below (Table 4):

Table 4. Efficiency indexes.

\begin{tabular}{cccccccc}
\hline Specimen & CUB-01 & CUB-02 & CUB-03 & CUB-04 & CUB-05 & CUB-06 & Average \\
\hline $\mathrm{ei}_{\mathrm{x}}$ & 0.33 & 0.36 & 0.29 & 0.33 & 0.36 & 0.37 & 0.34 \\
\hline $\mathrm{ei}_{\mathrm{y}}$ & 0.35 & 0.28 & 0.35 & 0.31 & 0.29 & 0.27 & 0.31 \\
\hline $\mathrm{ei}_{\mathrm{z}}$ & 0.33 & 0.37 & 0.36 & 0.37 & 0.36 & 0.36 & 0.36 \\
\hline
\end{tabular}

These indices are especially interesting in fiber-reinforced concretes, since it is possible to study if there is a correlation between pore orientation and fiber orientation.

\section{Conclusions}

The aim of this paper is to show the scientific possibilities offered by computed tomography for the study of porosity in concrete. For this purpose, six cubic specimens of $40 \mathrm{~mm}$ sides made of fiber-reinforced concrete were scanned. The data were then postprocessed using digital image processing software. As a result of this stage, all the pores of each specimen were identified and isolated, obtaining their individual properties, such as center of gravity coordinates, volume, length, orientations, etc.

Finally, all these data were sorted using different techniques in order to better understand the morphological characteristics of the pores and their spatial distribution. The main utilities provided by each of these techniques are mentioned below:

- Circumferential test: this allows detection of the presence of the wall effect, which manifests itself through changes in porosity as we approach the limits of the specimens. In addition, in damaged specimens it is very useful to determine crack distribution.

- Radial test: similar to the circumferential test, it is able to detect if there is any kind of wall effect. It can also be applied to specimens tested to failure to check whether the distribution of damage is uniform or if there are planes of weakness.

- Vertical test: this test is very useful to detect aggregate segregation in concrete, since in these cases it can be clearly observed that the porosity varies along the vertical coordinate.

- Neighborhood test: this test evaluates the degree of uniformity in pore distribution and can be very interesting to establish correlations with the macroscopic response of the concrete.

- Porosity curves and cumulative pore-volume curves: these curves are used to understand the pore size distribution. They are very useful in drawing comparisons between the porosity of different specimens, as well as in analyzing the influence of components or additives within the concrete matrix.

- Histograms of pore distribution and histograms of pore-volume distribution: These types of histograms, which can be plotted in volume or length ranges, can be used in addition to the previous graphs to gain an in-depth understanding of the concrete microstructure. The final objective is to try to explain the dispersion observed in the tests at the macroscopic level.

- Sphericity factor and shape factor: these parameters indicate the level of roundness of the pores; that is, how closely they approach a spherical shape. They can be used to determine whether pore shape influences crack initiation and propagation, or to evaluate the impact of components or additives on pore shape.

- Pore orientation: as it is shown that pores are not spherical, it is interesting to determine their orientations and check if there are correlations with the macroscopic response of the concrete. This parameter is particularly relevant in fiber-reinforced concrete. 
All these techniques reveal that computed tomography can provide a great deal of information on the porosity of concrete, much more than that given by conventional procedures. Although the technology has not yet reached a sufficient level of development, it is expected that in the next few years it will be possible to achieve resolutions well below $1 \mu \mathrm{m}$ in normal-sized specimens. This will make it possible, by applying the techniques presented in this work, to study the microstructure of concrete at a level never seen before.

Author Contributions: Conceptualization and methodology, M.A.V., Á.M., J.M. and D.C.G.; development and supervision of the test, M.A.V. and D.C.G.; post processing of the data provided by the test Á.M. and J.M.; founding acquisition and project administration, M.A.V. and D.C.G.; writing-original draft preparation, Á.M.; writing, reviewing and editing the paper, M.A.V., Á.M., J.M. and D.C.G. All authors have read and agreed to the published version of the manuscript.

Funding: This research was funded by the Ministerio de Economía y Competitividad, Gobierno de España (Spain); grant number PID2019-110928RB-C32.

Conflicts of Interest: The authors declare no conflict of interest.

\section{References}

1. Krause, M.; Hausherr, J.M.; Burgeth, B.; Herrmann, C.; Krenkel, W. Determination of the fibre orientation in composites using the structure tensor and local X-ray transform. J. Mater. Sci. 2010, 45, 888-896. [CrossRef]

2. Pittino, G.; Geier, G.; Fritz, L.; Hadwiger, M.; Rosc, J.; Pabel, T. Computertomografische Untersuchung von Stahlfaserspritzbeton mit mehrdimensionalen Transferfunktionen (Computer tomographic investigation of steel fiber reinforced sprayed concrete using multidimensional transfer functions). Beton Stahlbetonbau 2011, 106, 364-370. (In German) [CrossRef]

3. Suuronen, J.-P.; Kallonen, A.; Eik, M.; Puttonen, J.; Serimaa, R.; Herrmann, H. Analysis of short fibres orientation in steel fibre-reinforced concrete (SFRC) by X-ray tomography. J. Mater. Sci. 2013, 48, 1358-1367. [CrossRef]

4. Vicente, M.A.; González, D.C.; Mínguez, J. Determination of dominant fibre orientations in fibre-reinforced high strength concrete elements based on computed tomography scans. Nondestruct. Test. Eval. 2014, 29, 164-182. [CrossRef]

5. Kar, J.; Dinda, S.K.; Roy, G.G.; Roy, S.K.; Srirangam, P. X-ray tomography study on porosity in electron beam welded dissimilar copper-304SS joints. Vacuum 2018, 149, 200-206. [CrossRef]

6. Yu, W.; Sing, S.L.; Chua, C.K.; Tian, X. Influence of re-melting on surface roughness and porosity of AlSi10Mg parts fabricated by selective laser melting. J. Alloys Compd. 2019, 792, 574-581. [CrossRef]

7. Mehdikhani, M.; Gorbatikh, L.; Verpoest, I.; Lomov, S.V. Voids in fiber-reinforced polymer composites: A review on their formation, characteristics, and effects on mechanical performance. J. Compos. Mater. 2019, 53, 1579-1669. [CrossRef]

8. Garcea, S.C.; Wang, Y.; Withers, P.J. X-ray computed tomography of polymer composites. Compos. Sci. Technol. 2018, 156, 305-319. [CrossRef]

9. Maj, J.; Basista, M.; Weglewski, W.; Bochenek, K.; Strojny-Nędza, A.; Naplocha, K.; Panzner, T.; Tatarková, M.; Fiori, F. Effect of microstructure on mechanical properties and residual stresses in interpenetrating aluminum-alumina composites fabricated by squeeze casting. Mater. Sci. Eng. A 2018, 715, 154-162. [CrossRef]

10. Ibrahim, M.E. Nondestructive evaluation of thick-section composites and sandwich structures: A review. Compos. Part A Appl. Sci. Manufact. 2014, 64, 36-48. [CrossRef]

11. Vicente, M.A.; González, D.C.; Mínguez, J. Recent advances in the use of computed tomography in concrete technology and other engineering fields. Micron 2019, 118, 22-34. [CrossRef]

12. Mena, A.; González, D.C.; Mínguez, J.; Vicente, M.A. Computed tomography beyond medicine: Applications to the microstructural study of concrete and other engineering materials. Hormigón Acero 2020, 71, 7-19.

13. González, D.C.; Rahman, M.; Mínguez, J.; Vicente, M.A.; Hindi, R. Influence of Fibers and Curing Conditions on the Pore Morphology in Plain and Fiber-Reinforced High-Performance Concrete through the Use of Computed Tomography Scan Technology. Appl. Sci. 2020, 10, 4286. [CrossRef]

14. Li, Y.; Li, Y.; Guan, Z.; Ding, Q. Elastic modulus damage model of cement mortar under salt freezing circumstance based on X-ray CT scanning. Constr. Build. Mater. 2018, 191, 1201-1209. [CrossRef]

15. Trawiński, W.; Tejchman, J.; Bobiński, J. A three-dimensional meso-scale modelling of concrete fracture, based on cohesive elements and X-ray $\mu \mathrm{CT}$ images. Eng. Fract. Mech. 2018, 189, 27-50. [CrossRef]

16. Vicente, M.A.; González, D.C.; Mínguez, J.; Tarifa, M.A.; Ruiz, G.; Hindi, R. Influence of the pore morphology of high strength concrete on its fatigue life. Intern. J. Fatigue 2018, 112, 106-116. [CrossRef]

17. Olawuyi, B.J.; Boshoff, W.P. Influence of SAP content and curing age on air void distribution of high performance concrete using 3D volume analysis. Constr. Build. Mater. 2017, 135, 580-589. [CrossRef]

18. Huang, J.; Zhang, Y.; Sun, Y.; Ren, J.; Zhao, Z.; Zhang, J. Evaluation of pore size distribution and permeability reduction behavior in pervious concrete. Constr. Build. Mater. 2021, 290, 123228. [CrossRef] 
19. Rao, Y.; Yang, T. Three volumetric methods for measuring the vertical porosity distribution of pervious concrete pavement. Intern. J. Pavement Eng. 2021, 1-12. [CrossRef]

20. Liu, T.; Wang, Z.; Zou, D.; Zou, A.; Du, J. Strength enhancement of recycled aggregate pervious concrete using a cement paste redistribution method. Cem. Concr. Res. 2019, 122, 72-82. [CrossRef]

21. Liu, F.; Zhang, T.; Luo, T.; Zhou, M.; Ma, W.; Zhang, K. The effects of Nano-SiO 2 and $\mathrm{Nano}^{-\mathrm{TiO}} 2$ addition on the durability and deterioration of concrete subject to freezing and Thawing Cycles. Materials 2019, 12, 3608. [CrossRef]

22. Mínguez, J.; Vicente, M.A.; González, D.C. Pore morphology variation under ambient curing of plain and fiber-reinforced high performance mortar at an early age. Constr. Build. Mater. 2019, 198, 718-731. [CrossRef]

23. Vicente, M.A.; Mínguez, J.; González, D.C. Variation of the Pore Morphology during the Early Age in Plain and Fiber-Reinforced High-Performance Concrete under Moisture-Saturated Curing. Materials 2019, 12, 975. [CrossRef]

24. C. Analytics. Web of Science (Database), 1997. Available online: http:/ / webofknowledge.com/WOS (accessed on May 2021).

25. McNaugth, A.D.; Wilkinson, A. Compendium of Chemical Terminology. IUPAC Recommendations. Second Edition. Intern. Union Pure Appl. Chem. 2019. [CrossRef]

26. Le, H.T.; Kraus, M.; Siewert, K.; Ludwig, H.M. Effect of macro-mesoporous rice husk ash on rheological properties of mortar formulated from self-compacting high performance concrete. Constr. Build. Mater. 2015, 80, 225-235. [CrossRef]

27. Vydra, V.; Vodák, F.; Kapicková, O.; Hošková, Š. Effect of temperature on porosity of concrete for nuclear-safety structures. Cem. Concr. Res. 2001, 31, 1023-1026. [CrossRef]

28. Rouquerol, J.; Avnir, D.; Fairbridge, C.W.; Everett, D.H.; Haynes, J.H.; Pernicone, N.; Ramsay, J.D.F.; Sing, K.S.W.; Unger, K.K. Recommendations for the characterization of porous solids (Technical Report). Pure Appl. Chem. 1994, 66, 1739-1758. [CrossRef]

29. Tibbetts, C.; Tao, C.; Paris, J.M.; Ferraro, C.C. Mercury intrusion porosimetry parameters for use in concrete penetrability qualification using the Katz-Thompson relationship. Constr. Build. Mater. 2020, 263, 119834. [CrossRef]

30. Zeng, G.; Chen, S.; Yang, P.; Yu, P.; Wang, J.; Zhou, C.; Wang, Z.; Yan, D. Reassessment of mercury intrusion porosimetry for characterizing the pore structure of cement-based porous materials by monitoring the mercury entrapments with X-ray computed tomography. Cem. Concr. Compos 2020, 113, 103726. [CrossRef]

31. Sidiq, A.; Gravina, R.J.; Setunge, S.; Giustozzi, F. High-efficiency techniques and micro-structural parameters to evaluate concrete self-healing using X-ray tomography and Mercury Intrusion Porosimetry: A review. Constr. Build. Mater. 2020, 252, 119030. [CrossRef]

32. Xiaonan, W.; Wencui, Y.; Yong, G.; Decheng, F. The influence of shrinkage-reducing agent solution properties on shrinkage of cementitious composite using grey correlation analysis. Constr. Build. Mater. 2020, 264, 120194. [CrossRef]

33. Vincent, L.; Soille, P. Watersheds in digital spaces: An efficient algorithm based on immersion simulations. IEEE Trans. Pattern Anal. Mach. Intell. 1991, 13, 583-598. [CrossRef]

34. Vicente, M.A.; Ruiz, G.; González, D.C.; Mínguez, J.; Tarifa, M.; Zhang, X. CT-Scan study of crack patterns of fiber-reinforced concrete loaded monotonically and under low-cycle fatigue. Intern. J. Fatigue 2018, 114, 138-147. [CrossRef] 